\title{
20 years of microplasma research: a status report ${ }^{\star}$
}

\author{
Karl H. Schoenbach ${ }^{1}$ and Kurt Becker ${ }^{2, \text { a }}$ \\ 1 Frank Reidy Research Center for Bioelectrics, Old Dominion University, Norfolk, VA 23508, USA \\ 2 Department of Mechanical and Aerospace Engineering and Department of Applied Physics, New York University Tandon \\ School of Engineering, Brooklyn, 11201 New York, USA
}

Received 30 October 2015 / Received in final form 14 December 2015

Published online 4 February 2016

(C) The Author(s) 2016. This article is published with open access at Springerlink.com

\begin{abstract}
The field of microplasmas gained recognition as a well-defined area of research and application within the larger field of plasma science and technology about 20 years ago. Since then, the activity in microplasma research and applications has continuously increased. A survey of peer reviewed papers on microplasmas published annually shows a steady increase from fewer than 20 papers in 1995 to about 75 in 2005 and more than 150 in 2014. This count excludes papers that deal exclusively with technological applications where the microplasma is used solely as a tool. This topical review aims to provide a snap shot of the current state of microplasma research and applications. Given the rapid proliferation of microplasma applications, the topical review will focus primarily on the status of microplasma science and our understanding of the physics principles that enable microplasma operation. Where appropriate, we will also address microplasma applications, however, we will limit the discussion of microplasma applications to examples where the application is closely tied to the plasma science. No attempt is made to provide a comprehensive and in-depth review of the diverse range of all microplasma applications, except for the inclusion of a few key references to recent reviews of microplasma applications.
\end{abstract}

\section{Introduction}

Microplasmas, defined as plasmas where at least one dimension is in the submillimeter range, include microarcs and microsparks, which are generated by electrical breakdown in gases and in liquids. They are generated either by applying an overvoltage to electrodes or by focusing high power laser radiation into the discharge medium. These plasmas are generally thermal plasmas, where the gas temperature is far above the room temperature and is approaching the electron temperature. Another group of microplasmas, which is based on glow discharges, is nonthermal, with gas temperatures much below electron temperatures. Research in this area has undergone an enormous growth in the past two decades. Measured in terms of the number of publications per year research on this topic has over this time span increased almost by an order of magnitude. The attraction is based on the fact that such discharges can be operated stably at high gas pressures, in rare gases as well as in molecular gases, in a direct current (dc) mode as well as in pulsed dc and alternate current (ac) modes.

* Contribution to the Topical Issue "Recent Breakthroughs in Microplasma Science and Technology", edited by Kurt Becker, Jose Lopez, David Staack, Klaus-Dieter Weltmann and Wei Dong Zhu.

${ }^{a}$ e-mail: kurt.becker@nyu.edu
The first topical reviews in this field [1-3] published in 2005 and 2006 provided summaries of research into the basic properties of microplasmas and results from some of the applications of microplasmas that occurred in the first 10 years since the mid-1990s. Other review papers on microplasmas followed in 2008 and 2011 [4,5]. The most recent topical review paper which covers microplasmas, but expands the view to include transient, filamentary plasmas, was published in 2013 [6]. Other review papers, which focus on subsets of microdischarges and microdischarge applications, include those on UV light sources [7], microdischarge based sensors [8], photonic devices [9], guided ionization waves in plasma jets $[10,11]$ and microwavesustained microplasmas [12]. An application, which has gained strongly in interest by the scientific community is plasma medicine. Reviews on this topic have been published as early as 2005, and continue to be appear regularly in the literature. However, they typically cover only parts of this expanding research area [13-15].

Modeling and improved diagnostics have allowed us in the past decade to gain more insight into the physics of nonthermal microdischarges. At the same time, the range of applications has been expanding at a rapid pace. This topical review covers the basic science of microplasmas, as we know it now, and to show how the increased scientific knowledge has led to the development of new plasma technologies. It does not cover micro-arc discharges and micro-sparks in gases, but rather restricts the discussion 
to nonthermal microglow discharges. Also, this topical review provides only limited information on filamentary dielectric barrier discharges, which can be found in other reviews $[6,16]$. In this context, we note in particular that the work of Wagner, Brandenburg, and co-workers using cross-correlation spectroscopy [17-19] allows the characterization of the discharge breakdown and streamer development in single-filament dielectric barrier discharges.

For glow discharges, high pressure and small size are mutually consistent. This is based on similarity laws, which have been shown to hold not only for breakdown voltage (Paschen law), but can be extended to sustained glow discharges. The minimum axial dimension of a glow discharge between two parallel-plane electrodes is given approximately by the cathode fall length of a normal glow discharge. Shorter lengths are possible, but at the expense of a drastically increased voltage. According to the similarity laws, the cathode fall length is inversely dependent on the pressure, p. Minimizing the axial dimension of a normal glow discharge thus requires maximizing the pressure. The product of cathode fall thickness and pressure depends on cathode material and type of gas. It varies between 0.23 Torr $\mathrm{cm}$ for an air discharge between copper electrodes to 1.45 Torr $\mathrm{cm}$ for $\mathrm{He}$ discharges between $\mathrm{Mg}$ electrodes [20]. Assuming an average value of 1 Torr $\mathrm{cm}$, reducing the thickness of the discharge plasma to $100 \mu \mathrm{m}$ requires increasing the pressure to about 100 Torr, for $10 \mu \mathrm{m}$ to more than atmospheric pressure. However, the similarity laws, on which this estimate is based, rely on the assumption that the electron generation at the cathode is due to ion impact. Experimental studies on microgaps [21,22] showed that for gaps in the micrometer range, the breakdown voltage actually decreases with decreasing electrode spacing, d, instead of increasing, as expected from the Paschen law (Fig. 1). This deviation from the Paschen curve for very small gaps $(>2 \mu \mathrm{m})$ is likely caused by pure field emission (Fowler-Nordheim field emission) and, in the transition region (up to about $10 \mu \mathrm{m}$ ), through ion-enhanced field emission caused by the presence of positive ions near the cathode surface [23].

The smallest gaps for which the breakdown voltage in atmospheric-pressure gas (air and $\mathrm{N}_{2}$ ) was measured were approximately half a micrometer $[26,27]$. Since the electrical breakdown voltage in such small gaps is strongly affected by the surface roughness of the electrodes [28], reproducible electric field breakdown results for these extremely small gaps could only be obtained by polishing the electrodes to a very high finish $[26,27]$.

Whereas the minimum axial dimension of a glow discharge is likely determined by the surface roughness of the electrodes, the limitations in the transverse direction is determined by the transition from a normal glow discharge to a subnormal glow discharge. Reducing the current in a normal glow discharge causes a reduction in the diameter of the cathode fall area. When the diameter reaches values on the order of the cathode fall length (dark space at the cathode), the discharge voltage rises [29]. This increase is due to the increased radial losses of charged par-

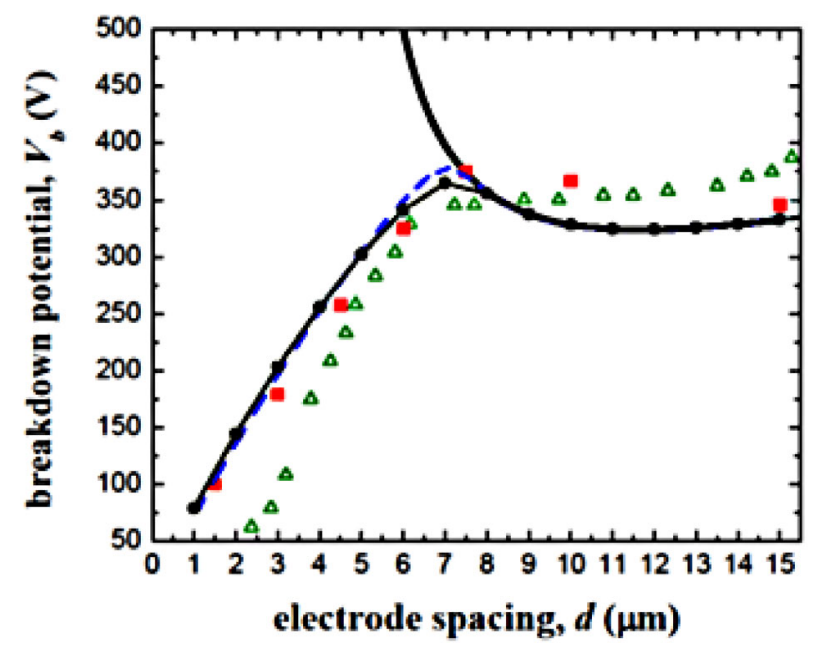

Fig. 1. Breakdown potential as a function of the electrode spacing. The bold solid curve shows the Paschen curve for atmospheric pressure air, between electrodes with a secondary emission coefficient of $\gamma=0.0075$. Experimental studies [22] show clearly the strong deviation of the breakdown potential from Paschen's law at very small gaps. The results of particlein-cell and Monte Carlo simulations (squares) [24] and that of recently developed analytical models [23] (solid line with filled circles), [25] (dashed line), which include ion-enhanced field emission as a major charge generation mechanism in small gaps, agree well with the experimental results (figure courtesy of David Go, University of Notre Dame).

ticles. Based on these considerations, and assuming that the thickness of the cathode fall region is determined by values of $\mathrm{pD}$ in the range of 0.5 to 1 Torr $\mathrm{cm}$, the minimum size of an atmospheric pressure glow discharge in the lateral direction is about $10 \mu \mathrm{m}$. Since this value is based on the lateral loss processes of the filamentary glow discharge, it is likely not dependent on the electron generation mechanism (ion impact or field emission) at the cathode.

Minimum size atmospheric-pressure glow discharge plasmas generated between plane parallel electrodes are consequently disk shaped with radial dimensions on the order of $10 \mu \mathrm{m}$. Their axial dimensions are dependent on the surface roughness of the electrodes, and consequently even for highly polished electrodes are not much below $1 \mu \mathrm{m}$. Theoretically, the smallest dimension of a microdischarge is determined by the Debye length, $D_{b}$.

$$
D_{b}=\left(\varepsilon k T_{\mathrm{e}} / n_{\mathrm{e}} e^{2}\right)^{1 / 2}
$$

with $\varepsilon$ being the permittivity, $k T_{\mathrm{e}}$ the electron energy, $n_{\mathrm{e}}$ the electron density, and e the electron charge. With measured electron densities in high pressure micro-glow discharges greater than $10^{14} \mathrm{~cm}^{-3}$ and average electron energies of approximately $1 \mathrm{eV}$ - not considering the high energy tail of the electron energy distribution - typical Debye lengths are less than $0.35 \mu \mathrm{m}$, which is less than the minimum axial dimension of a microdischarge determined by the electrode surface roughness. 


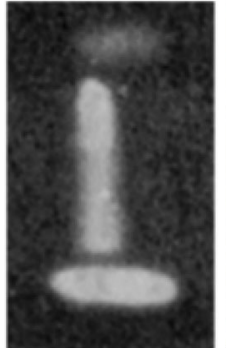

a

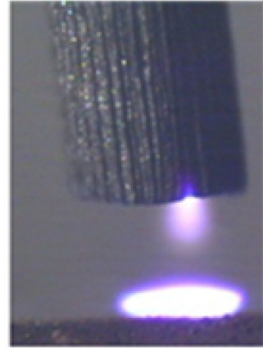

b

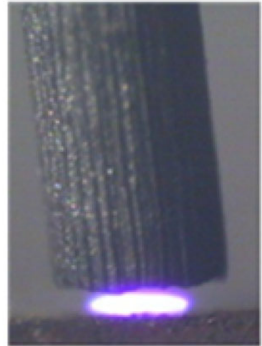

Fig. 2. (a) Glow discharge in atmospheric-pressure air between cooled copper electrodes (anode: top; cathode: bottom). The gap was $2 \mathrm{~mm}$ [30]. The radially extended luminous area close to the cathode is the negative glow. (b) and (c) Images of a glow discharge in atmospheric pressure air at (b) $0.5 \mathrm{~mm}$, (c) $0.1 \mathrm{~mm}$ electrode spacing [31].

\section{Microdischarges between parallel-plate electrodes}

\subsection{DC micro-glow discharges between parallel-plate electrodes}

An image of an atmospheric-pressure "micro" glow discharge in air, obtained in one of the early studies on highpressure glow discharges between plane parallel electrodes, is shown in Figure 2a [30]. The gap is $2 \mathrm{~mm}$. Studies with even smaller gaps show clearly the presence of a positive column and a very distinct extended luminous area, the negative glow for gaps larger than $0.1 \mathrm{~mm}$ (Fig. 2b) [31]. For gaps as small as $0.1 \mathrm{~mm}$, the positive column has disappeared, and the discharge in axial direction consists of cathode fall and negative glow only (Fig. 2c).

A problem in operating micro-glow discharges at high pressures is the quadratic increase in current density with pressure. Experimental results for a glow discharge in atmospheric-pressure air between copper electrodes show that for atmospheric-pressure air the current density approaches values on the order of $10 \mathrm{~A} / \mathrm{cm}^{2}$ [30]. The power density in a microdischarge with dimensions on the order of the cathode fall, $d_{n}$ (approximately $100 \mu \mathrm{m}$ at atmospheric pressure air), and assuming a cathode fall voltage of $150 \mathrm{~V}$, reaches therefore values exceeding $10^{5} \mathrm{~W} / \mathrm{cm}^{3}$. This, in turn, causes strong heating of the plasma and eventually the transition from a nonthermal, diffuse glow discharge to a thermal, filamentary arc discharge (glow-toarc transition). The earliest attempts to generate (micro) glow discharges between parallel plate electrodes at atmospheric pressure have used cooling of the cathode as a means to limit the plasma temperature. Another way to prevent such a transition is to limit the duration of the discharge to times shorter than the time required for the development of such an instability, usually times below one microsecond.

Since high-pressure, direct-current discharges between plane parallel electrodes are characterized by a negative differential voltage-current, $d V / d I$, characteristic (an example is shown in Fig. 3), they require stabilization at

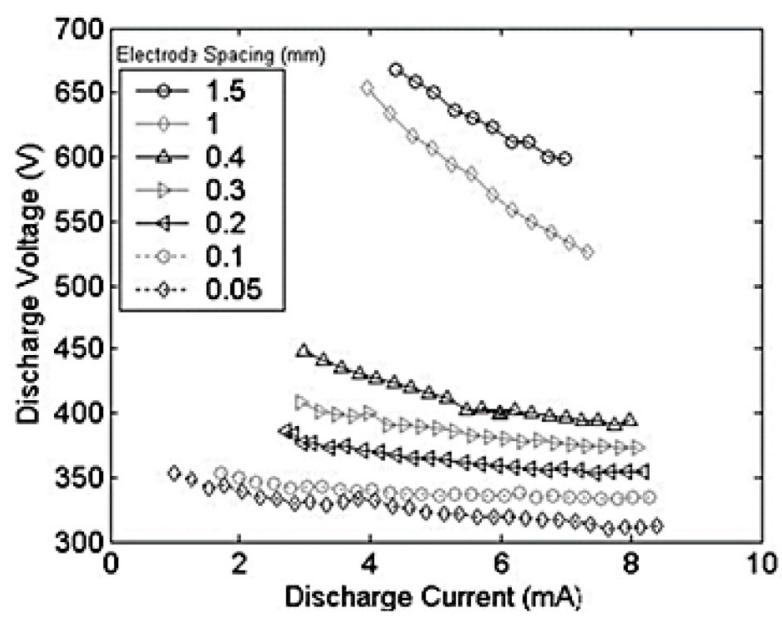

Fig. 3. Voltage-current characteristic for plasma discharges in atmospheric-pressure air at several electrode spacings [31].

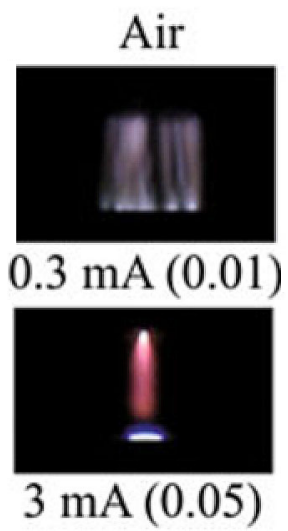

Fig. 4. Images of atmospheric-pressure gas discharges in air with an electrode gap of $1 \mathrm{~mm}$. Upper part: oscillating discharges; lower part: stable, normal glow discharges. The numbers in the brackets denote the time of open camera shutter in seconds [34].

current levels below the transition from glow-to-arc, generally obtained by using a ballast resistor. The resistance, $R$, of the ballast resistor in series with the glow discharge is determined by the Kaufmann criterion [32]:

$$
d V / d I+R>0 .
$$

This can be understood by the fact that any fluctuation in the discharge current, $I$, which causes a negative change in voltage, $V$ (in a discharge with negative differential voltage characteristic), is automatically quenched by an equal and opposite voltage across the resistor $R$ [33].

Another instability is observed when the current is reduced at constant pressure. The normal glow discharge, as seen in Figure 4 (lower part) for air at atmospheric pressure, changes into a subnormal glow discharge (upper part), which requires a higher sustaining voltage. Charging of the interelectrode capacitance, $C$, through the ballast resistor, $R$, during the time of the subnormal glow allows the establishment of a normal glow again, however, only for the time it takes to discharge the capacitance $C$. 

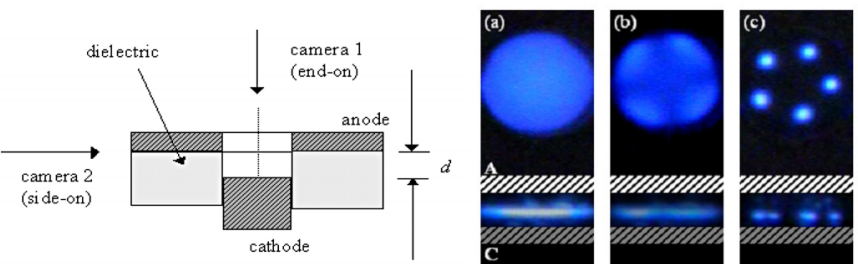

Fig. 5. Left side: cross-sectional view of the electrode configuration of a CBL discharge. The diameter of the circular opening of the anode and the transparent borosilicate dielectric varies between $300 \mu \mathrm{m}$ and $750 \mu \mathrm{m}$. The thickness of the dielectric is $250 \mu \mathrm{m}$ and that of the anode is $100 \mu \mathrm{m}$. Right side: Endon (top) and side-on (bottom) observations of CBL discharges in 75 Torr $\mathrm{Xe}$, at the transition from homogeneous discharge to patterned discharge (a: $0.22 \mathrm{~mA}$; b: $0.18 \mathrm{~mA}$; c: $0.09 \mathrm{~mA}$ ). The side-on views between anode $\mathrm{A}$, and cathode $\mathrm{C}$, show a reduced cathode fall length (dark space) with transition to a self-organized structure [37].

This process repeats itself and causes an oscillating (selfpulsing) behavior, with a frequency dependent on the RC time of the circuit [34].

\subsection{DC micro-glow discharges between a flat cathode and ring-shaped anode - cathode boundary layer discharges}

Figure 2 shows an extended area of high luminosity close to the cathode, which has been identified as the negative glow, a plasma of relatively high conductivity bordering the cathode fall area. By replacing the parallel plate anode with a ring-shaped anode surrounding the negative glow, i.e. separated from the cathode only by a distance on the order of the cathode fall, the negative glow is used as a virtual anode, carrying not only an axial current as in conventional glow discharges, but also a transverse current toward the physical ring-shaped anode. This type of discharge, which allows open visual access in the axial direction, was named cathode boundary layer discharge (CBL discharge) [35,36].

The electrode configuration for such a discharge is shown in Figure 5a. End-on images of the CBL discharge in 75 Torr Xe (right) show, with decreasing current, the transition from a homogenous discharge to a patterned one with radially symmetric filaments developing at the area closest to the ring-shaped anode. The side-on view of the discharge has been obtained by using a transparent dielectric: borosilicate [37]. Another end-on view in the visible range of the spectrum of such a discharge plasma in Xe is shown in Figure 6 for pressures of 50 Torr (Fig. 6a) and 100 Torr (Figs. 6b-6d) and varying currents [38]. It shows that by reducing the current by even small amounts the filamentary pattern turns into a ring-shaped pattern, and eventually is reduced to a single filament right on axis. The diameter of the filament is approximately $70 \mu \mathrm{m}$ in the case of $\mathrm{Xe}$ at 50 Torr. Increasing the pressure allows one to reduce the diameter even further, since the diameter corresponds to the length of the cathode layer dark

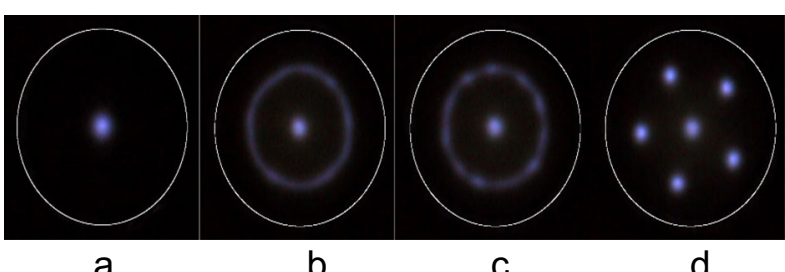

C

d

Fig. 6. (a) Single plasma spot observed at a Xe pressure of 50 Torr and $0.05 \mathrm{~mA}$; (b) target shape plasma pattern at 100 Torr and $0.132 \mathrm{~mA}$; (c) target shape plasma pattern with clear nodes at 100 Torr and $0.137 \mathrm{~mA}$, and (d) six plasma spots observed at 100 Torr and $0.136 \mathrm{~mA}$ [38].

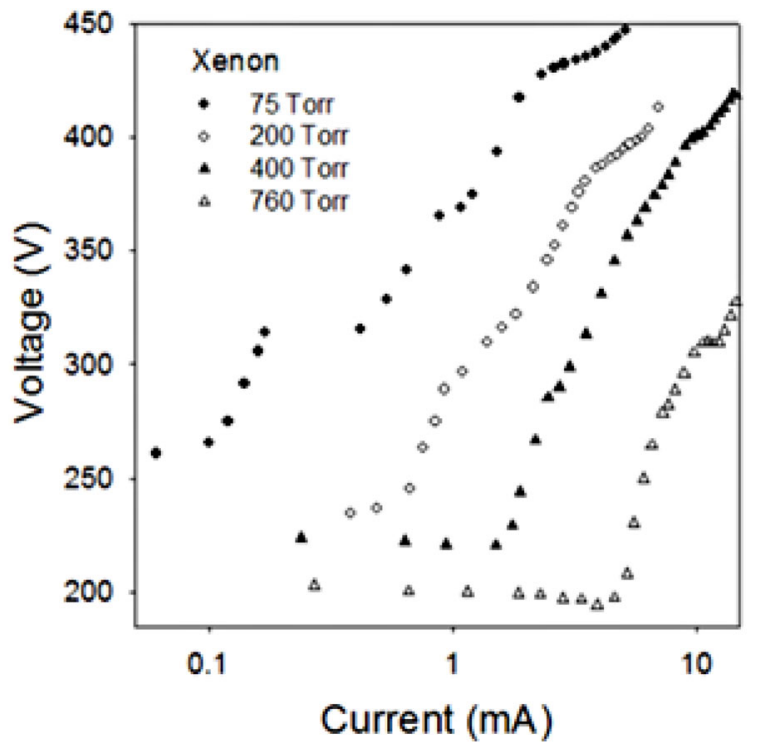

Fig. 7. $V-I$ characteristics of $\mathrm{Xe}$ CBL discharges at various pressures. The cathode opening is $1.5 \mathrm{~mm}$ in diameter [36].

space. Since the cathode layer dark space is inversely linearly dependent on the pressure [26], filament diameters of about $10 \mu \mathrm{m}$ should be obtainable for atmospheric pressure. Whereas initially these self-organized patterns were only observed in Xe CBL discharges, more recent studies have also shown the existence of such structures in $\mathrm{Kr}$ discharges [39].

Theoretical studies aimed at an explanation of the reason for such self-organization in CBL discharges, but also in other types of glow discharges and arc discharges, show that a 2D treatment of glow discharges including diffusion of the charged particles in the lateral direction provides multiple solutions for the same discharge current. A description of the mathematical formulation of the theory of multiple solutions and a discussion of the various patterns in CBL discharges can be found in the review by Benilov [40].

The voltage-current $(V-I)$ characteristics of CBL discharges, at least in $\mathrm{Xe}$, has a positive slope over a wide range of currents (Fig. 7) even at atmospheric pressure. This is quite different from atmospheric-pressure discharges between plane-parallel electrodes in noble gases [34] and in air as shown in Figure 3 [31]. This means, 


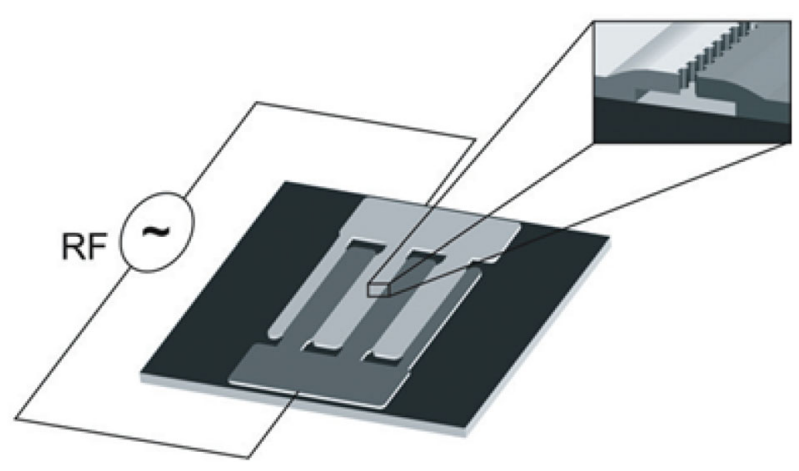

Fig. 8. Schematic view of a micro-structured electrode (MSE) array with the electrode gap design shown in detail [41].

that stabilization of such discharges does not require ballast resistors, and that they can therefore be easily operated in parallel (see section on Microdischarge Arrays).

\subsection{AC (Microwave) micro-glow discharges between parallel edge electrodes}

Radiofrequency (rf) sustained microdischarges in planar electrode systems, bonded to dielectric substrates, also allow to generate plasmas in atmospheric-pressure gases. An electrode system (Microstructured Electrode Array) is shown in Figure 8 [41,42]. The electrode gap, shown enlarged in the insert, has a width of $70 \mu \mathrm{m}$. With this electrode gap it was possible, using a $13.56 \mathrm{MHz}$ generator, to ignite microdischarges at voltages below $390 \mathrm{~V}$ even in atmospheric-pressure air.

Increasing the frequency into the microwave range $(>0.3 \mathrm{GHz})$ provides new opportunities for the generation of microdischarges [12]. There are two topologies for coupling microwaves into microdischarges (Fig. 9). The upper part (a) of Figure 9 shows the equivalent circuit and the voltage distribution along the transmission line, which connects source and load, i.e. the discharge. Before the discharge is ignited, the voltage wave is reflected from the open circuit and forms a standing wave on the transmission line. When the plasma is ignited and matched to the source, generally a $50 \Omega$ source, the voltage drops to half of this values. Operation in this mode requires either a high power microwave source or an external ignition source for atmospheric pressure discharges.

A second concept is shown in Figure 9b. It shows a quarter wave resonator system, with the end of the transmission line opposite to the load end shortened. Power is applied at an intermediate position, where the impedance is $50 \Omega$. Before the discharge is ignited, the load site acts as an open circuit, and the voltage at this end builds up to values on the order of $Q$ times the initial voltage, where $Q$ is the quality factor of the resonator. This causes breakdown in the gap and subsequently a drop in the quality factor of the resonator due to absorption in the plasma. A photograph of such a resonator with and without microplasma is shown in Figure 10.
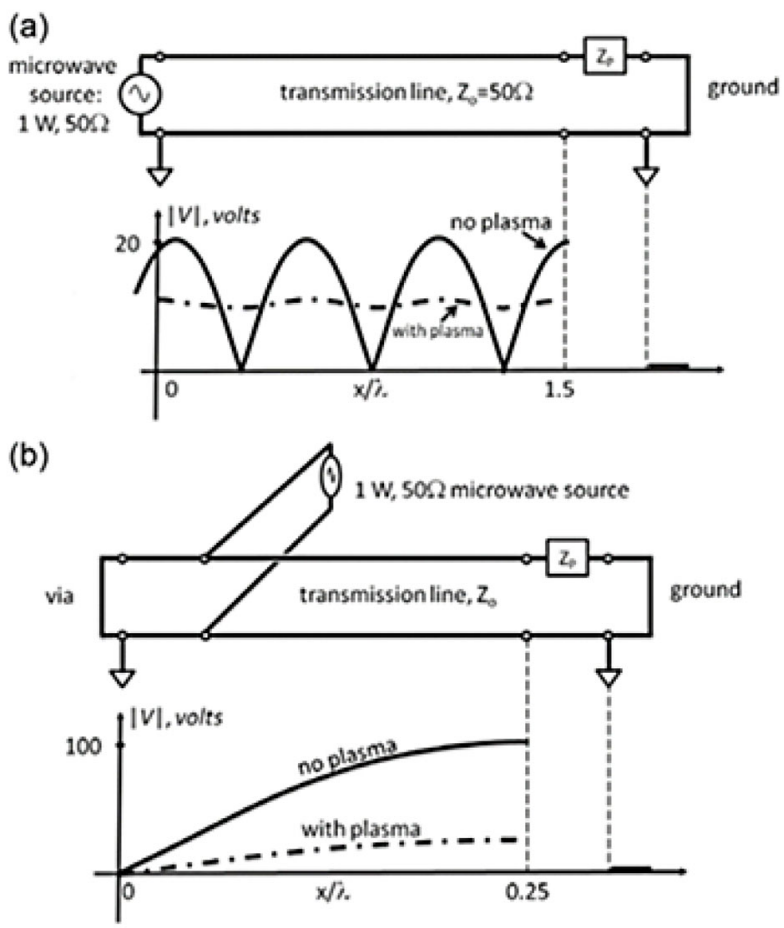

Fig. 9. Transmission line equivalent circuit (a) using a simple transmission line, and (b) a quarter wave generator. The solid lines represent the voltage distribution before plasma ignition, the dashed line shows the voltage distributions with the plasma present [12].

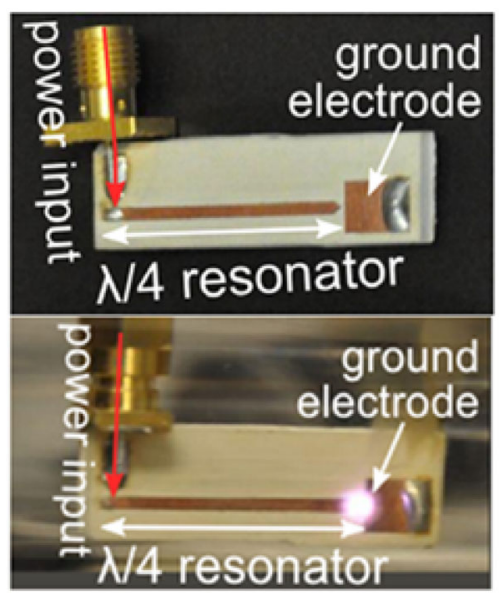

Fig. 10. Photographs of a $1 \mathrm{GHz}$ quarter-wave generator show a $20 \mathrm{~mm}$ long microstrip device with (bottom) and without (top) a microplasma [12].

An important parameter in the operation of microwave-sustained microdischarges is the microwave frequency. At low frequencies and/or small gaps the amplitude of the electron oscillation is larger than the discharge gap, and the electrons are lost to the electrodes. Operation of the discharge in this mode is called the $\gamma$-mode, since the ionization in such discharges is driven by secondary electrons from the electrodes. At high frequencies and/or larger gaps, the amplitude of the electron oscillation is 


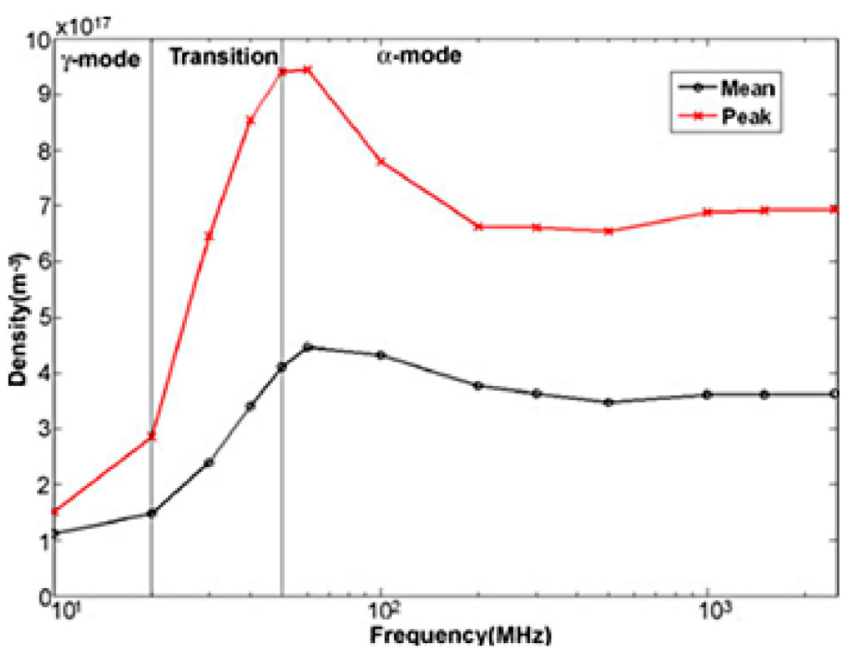

Fig. 11. Peak and mean electron density as a function of the rf frequency in an atmospheric-pressure He discharge between plane-parallel electrodes $500 \mu \mathrm{m}$ apart [43].

less than the gap length and the electrons are trapped in the discharge gap, a mode called the $\alpha$-mode, where the ionization processes are confined to the bulk of the plasma. For atmospheric-pressure Ar microplasmas in a gap of $100 \mu \mathrm{m}$, the frequency needs to extend $250 \mathrm{MHz}$ to operate the discharge in the $\alpha$-mode.

Increasing the frequency to values exceeding that required for the $\gamma$-mode and keeping the incident power constant causes an increase in plasma density due to a more efficient coupling of the input power to the electrons. A conventional fluid model that solves the continuity equation for each plasma species together with the electron energy equation and Poisson's equation was used to model a $500 \mu \mathrm{m}$ parallel plate microdischarge driven at constant input power with a $10 \mathrm{MHz}-2.45 \mathrm{GHz}$ voltage source in atmospheric-pressure He [43]. The results (Fig. 11) show clearly the strong rise in electron density in the transition region from the $\gamma$-mode to the $\alpha$-mode. Consequences of operating the discharge in the $\alpha$-mode are also a reduction in the breakdown voltage (microwave power) and less sputtering by ions, which results in an increase in the lifetime of such discharges.

\section{From planar to microcavity electrode structures}

Most of the applications of microdischarges described later in this manuscript are based on placing them in parallel in order to utilize them in lighting, material processing, plasma medicine, etc. In order to arrange them in parallel without using individual ballast resistors, the voltage-current characteristics of such discharges needs to have a positive slope according to the Kaufmann criterion (Eq. (2)). The simplest electrode configuration, planeparallel metal electrodes, does not satisfy the requirement of a positive $d V / d I$, and is, consequently, inherently unstable. It requires for parallel operation a ballast resistor in series to the discharge, which for array formation not

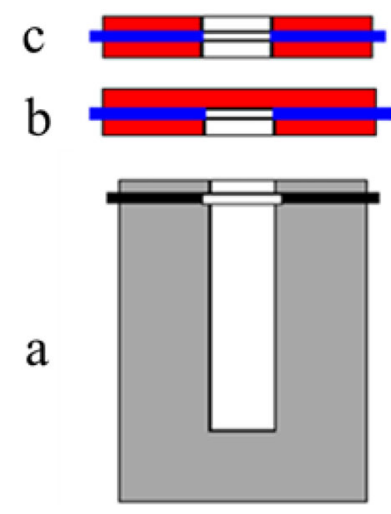

Fig. 12. Cross sections of three types of micro-hollow cathode (electrode) structures. The electrodes are separated by a dielectric layer (black in (a), blue in (b) and (c)). In (a) and (b), the anode is the top electrode.

only makes the design more complicated, but also causes a reduced efficiency due to the energy loss in such resistors.

A way to stabilize a high-pressure microdischarge is to use a built-in loss mechanism. By confining the plasma in small metallic cavities (the electrodes) and dielectric cavities (between the electrodes), thermal conduction to the electrodes and diffusion to the walls of the dielectric layer between the electrodes effectively damps small fluctuations in the plasma, which otherwise would lead to instabilities. For high-pressure discharges, these cavity dimensions need to be in the $100 \mu \mathrm{m}$ range. With this approach it is possible to extend the pressure and current density range and to generate stable glow discharges at pressures up to and above one atmosphere, even in molecular gases without using ballast resistors.

However, even though thermal instabilities can be suppressed by confining the discharges in microcavities, selfpulsing, similar to what was shown in discharges between parallel-plate electrodes [34], is still observed. However, it only occurs when the discharge current exceeds a threshold value, rather than for low currents [44]. This effect is based again, as discussed in reference [45], on the external circuit, and can be controlled by using appropriate ballast resistors.

\subsection{Microhollow cathode (microcavity) discharges}

The stability of dc glow discharges confined in small cavities was first reported by White [46], who studied hollow cathode discharges in 100 Torr Ne with the cathode containing a nearly spherical cavity of $750 \mu \mathrm{m}$ diameter and a pin anode. In 1996, stable discharges in air at pressures of 350 Torr were generated in an electrode geometry shown in Figure 12a by reducing the dimensions of the cylindrical hole in a molybdenum cathode to a diameter of $75 \mu \mathrm{m}$ [47].

It was found later that reducing the depth of the cathode hole had only a minor influence on the discharge characteristics, and consequently, the cathode hole was reduced to a ring-shaped cathode with a thickness comparable to the hole diameter [44]. The anode was 
either planar (Fig. 12b) or ring-shaped as the cathode (Fig. 12c). This "sandwich" micro-hollow cathode (MHC) discharge configuration has subsequently also be used by other research groups, but sometimes under a different name, such as three-dimensional Microstructured Electrode (MSE) discharge [48].

\subsubsection{DC operation of microcavity discharges}

The phrase "hollow cathode discharge" historically refers to a specific mode of discharge operation, where the cathode fall regions in the interior of the cylindrical cathode are so close that high energy electrons emitted from one side of the cathode can enter the opposite cathode fall, where they are accelerated back towards the axis. This "pendulum" motion of the electrons leads to increased ionization on the hollow cathode axis, which appears in the current-voltage curve as negative differential resistance [49].

A simple estimate of the hole diameter and pressure range, where a hollow cathode discharge can exist, is based on the assumption that the cathode fall lengths for a normal glow discharge, $d_{n}$, in the cylindrical hole need to be equal or larger than the hole radius, $D / 2$. From similarity laws for normal glow discharges, $d_{n}$ is inversely proportional to the pressure. Assuming that the product of cathode fall length, $d_{n}$, and pressure $p$ is approximately 1 Torr cm (see also "Introduction"), the hole diameter range for hollow cathode discharges in the cylindrical hole is given as:

$$
D p<2 \text { Torr cm. }
$$

For a $D=200 \mu \mathrm{m}$ wide cathode hole, hollow cathode discharges are, therefore, expected to exist as long as the pressure is below 100 Torr. Indeed, first studies with Ar in MHC (Micro Hollow Cathode) discharge systems as shown in Figure 12b, indicated that the observed discharges were of the hollow cathode type [44]. As shown in Figure 13, after an increase in voltage with current at low levels, the voltage decreases first drastically, later with a smaller negative slope, due to the increased ionization caused by pendulum electrons. With increasing current, the discharge in the hole turns into a normal glow discharge followed by an abnormal glow discharge as indicated by the slight increase in voltage.

The luminous part of the discharge, where the negative glows of the cathode falls from opposite sides of the cylindric cathode overlap is for this discharge clearly located in the center of the hole, with the maximum in luminosity on axis (Fig. 13).

In later experiments at higher pressures, but similar hole diameters, the appearance of the plasma inside the cathode hole changed, as shown in Figure 14 (top) [50], As in Figure 13, the photographs provide a view of the cathode side of a discharge system as shown in Figure 12b. The luminous plasma develops along the edge of the hole, and, for high currents, even outside the hole. Although there is still a range of currents where the $V-I$ characteristic has

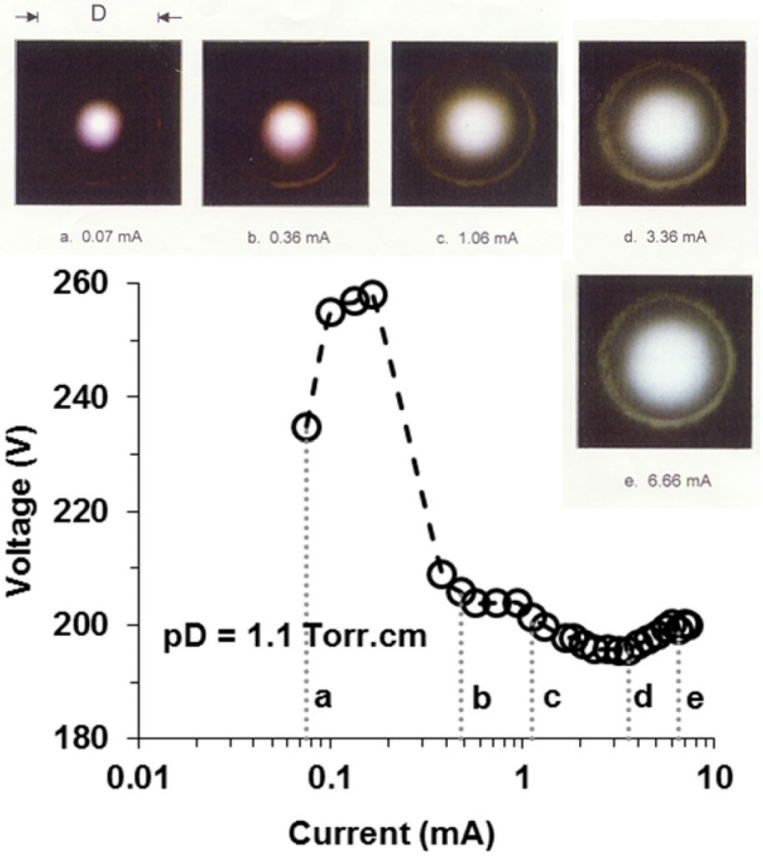

Fig. 13. End-on photographs of MHC discharges in Ar at 56 Torr. The cathode hole diameter was $200 \mu \mathrm{m}$. Shown is the discharge development with increasing current (top) and the dc current-voltage characteristics of these discharges (bottom) [44].

a negative slope, the underlying mechanism is no longer related to the hollow cathode (pendulum) effect.

Modeling of a MHC discharge with Dp values larger than the critical value for hollow cathode discharges (Eq. (3)) showed that the positive voltage-current characteristics at low currents can be attributed to an abnormal glow inside the hole, and the flat part at high currents to a normal glow discharge developing on the flat surface of the cathode outside the hole [51]. The superposition of the two discharges provides a range where the voltage-current characteristics have a negative slope (Fig. 15), similar to that obtained in hollow cathode discharges. Since microdischarges with a cathode hole operated at $p D>2$ Torr $\mathrm{cm}$ are characterized by a different mechanism than the original microhollow cathode discharges, MHC discharges are often simply referred to as microdischarges.

Whereas the first microcavity cathodes made from molybdenum were generated by mechanical drilling and later, laser drilling, other groups focused early on the use of microfabrication techniques. Eden and co-workers used silicon as electrode material [52]. The motivation for this approach is the ability to controllably and reproducibly machine a wide range of features at the micro- and even nano-scale. With this technology, it was possible to reduce the width of the cathode hole to values of $10 \mu \mathrm{m}$ (with length of $30 \mu \mathrm{m}$ ), and to operate the discharges in Ne in a pressure range from 700 Torr to 1100 Torr (Fig. 16) [53]. The $p D$ values ranged from 0.7 to 1.1 Torr $\mathrm{cm}$. Although a ballast resistor of $1 \mathrm{M} \Omega$ was used, the resistance (expressed by the positive $I-V$ slope) of the discharge is much higher, 


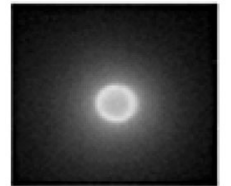

a

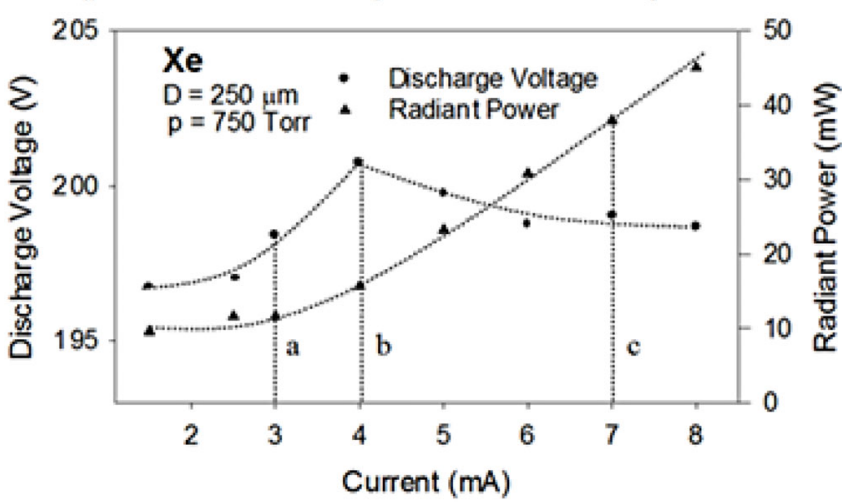

Fig. 14. Top: end-on images of MHC discharges in atmospheric pressure Xe. The corresponding radiant power of the excimer emission at a wavelength of $175 \mathrm{~nm}$ is shown in the lower graph. Also shown in this graph is the voltage-current characteristic of these discharges [50].

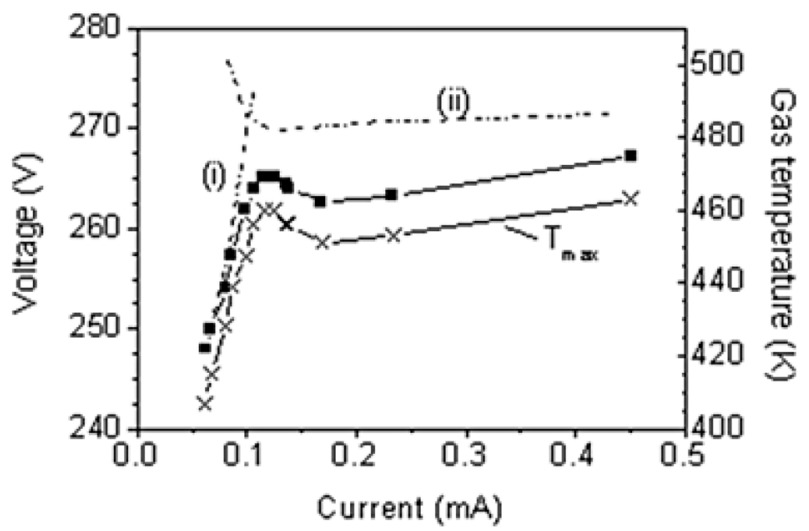

Fig. 15. Calculated $V-I$ characteristic (ם) and peak gas temperature $(x)$ vs. current (Xe, 100 Torr; $D=280 \mu \mathrm{m})$. The dashed lines (i) and (ii) are characteristics calculated for discharges sustained by electron emission from inside the hollow cathode or from the outer surface of the cathode, respectively [51].

on the order of $100 \mathrm{M} \Omega$, and consequently, the discharges operating in this mode will not require external stabilization. The positive slope indicates that the discharges are operating at the boundary of either a pre-hollow cathode mode [54] or an abnormal glow mode in the cathode hole. Both mechanisms provide the observed positive slope in the voltage-current characteristic.

A variation of the original MHC discharge configurations (Fig. 12) is the use of capillary tubes as hollow cathodes with inner diameters in the $100 \mathrm{~s}$ of micrometer range (Fig. 17) [55]. The anode is a metal grid with a variable distance (in the $\mathrm{mm}$ range) from the cathode opening. This geometry, which allows the formation of stable, high-

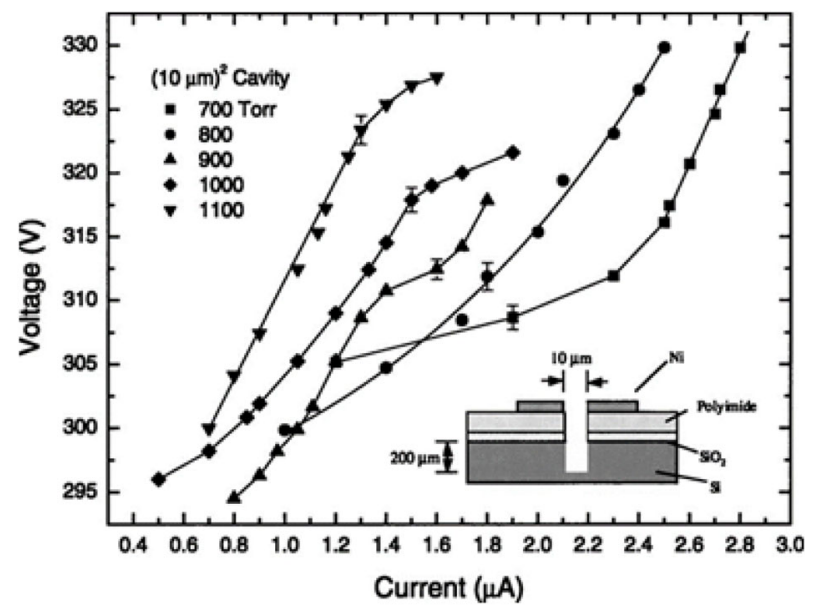

Fig. 16. $V-I$ characteristics of $10 \mu \mathrm{m}$ silicon trench microcathode devices operating in neon at various pressures. The inset shows a generalized schematic diagram of the device structure [53].

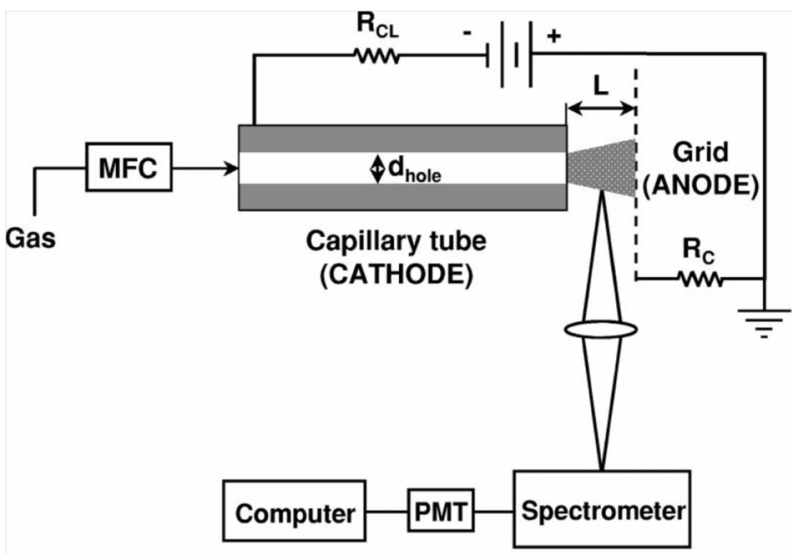

Fig. 17. Schematic diagram of a hollow cathode plasma microjet with optical emission spectroscopy setup [55].

pressure plasma microjets, has been used successfully in nanomaterial synthesis [56].

Some MHC discharge geometries different from the ones shown in Figure 12a, employ inverse pyramidal holes and trenches. These structures have been studied by Eden et al. [9]. The use of inverse pyramidal cathode holes, generated by means of Si-edging allowed the production of large arrays of microcavity discharges [57]. The crosssection of such an inverted pyramidal cathode is shown in Figure 18b. Other microcavity geometries have utilized microslots, where the cylindrical cathode openings are replaced by slits [58-60].

\subsubsection{AC operation of microcavity discharges}

Although most of the basic studies and modeling efforts have been performed on direct current microcavity discharges, efforts at many laboratories have been devoted to developing alternating current microcavity discharges. 
(a)

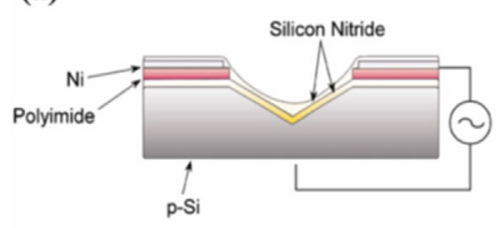

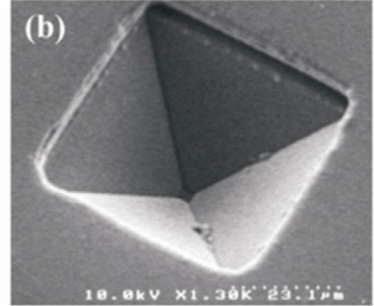

Fig. 18. (a) Cross-sectional diagram of a Si microplasma device with an inverted square pyramid microcavity and a dielectric structure designed for ac or bipolar operation; (b) SEM of a single device viewed from above. The emitting aperture (pyramid base dimensions) for this device is $50 \times 50 \mu \mathrm{m}^{2}$ [2].

Studies of rf-driven microdischarges in hollow slot electrode geometries were reported by Collins et al. [58,59], and rf microdischarge arrays were studied at the $\mathrm{Na}$ tional Cheng Kung University in Taiwan [61]. Planar micro-structured electrode (MSE) Arrays operated at rf were successfully used to generate atmospheric-pressure microplasmas $[41,42]$.

The use of ac voltages allows coating of the electrodes with insulating materials and, consequently, leads to an increased lifetime of such barrier discharge systems. With $\mathrm{Si}$ as cathode material coated with a thin film of silicon nitride (Fig. 18a), large arrays of microdischarges can be fabricated using micromachining techniques [62]. Such microcavity devices can also be addressed individually for use in displays. This has been shown for an array operating in Ne at 500 Torr using a split top electrode design with an rms voltage as low as $240 \mathrm{~V}$ [63].

The use of polymer-based replica molding processes by the group at the University of Illinois allowed fabrication of flexible arrays of microcavity plasma devices [64]. These discharges where run at ac in the range of 15 to $20 \mathrm{kHz}$. Linear, atmospheric-pressure oxygen plasmas with trapezoidal or parabolic profile, generated within nanoporous alumina microchannels were studied more recently by this group [65,66]. An example of the design and an image (in the visible spectrum) of such a discharge in atmosphericpressure air is shown in Figure 19.

\subsubsection{Pulsed operation of microcavity discharges}

Operation of single dc MHC discharges with currents exceeding about $8 \mathrm{~mA}$ leads to thermal damage even to molybdenum electrodes. However, by operating the discharge in a pulsed dc mode, the current can be increased considerably, as demonstrated with pulses of $0.7 \mathrm{~ms}$ duration and a repetition rate of $10 \mathrm{~Hz}$ in a $\mathrm{MHC}$ discharge electrode geometry [67]. The pulsed operation allows increasing the current from 8 to $80 \mathrm{~mA}$, limited only by the onset of instabilities. This increase in current is related to an increase in the area of the plasma layer on top of the cathode surface, a phenomenon similar to that shown in Figure 14 (top). The current density stays constant with increasing current, typical for a normal glow discharge, and in accordance with an MHC discharge model [51].

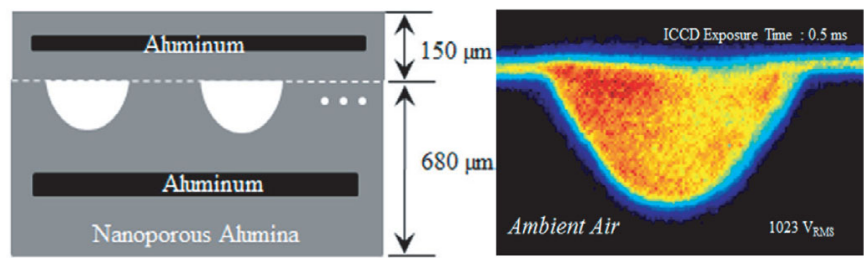

Fig. 19. (Left) Cross-sectional diagram of a dielectric barrier discharge microchannel plasma device - a fully $\mathrm{Al} / \mathrm{Al}_{2} \mathrm{O}_{3}$ device incorporating two $\mathrm{Al}$ electrodes. Such devices are hermetically sealed and the cavity cross-section can be changed from parabolic to trapezoidal. (Right) A false color image $(0.5 \mathrm{~ms})$ of a discharge in ambient pressure air. The discharge was driven by a $20 \mathrm{kHz}$ voltage of $1023 \mathrm{~V}$ [65].

Whereas the use of pulsed dc with pulse durations in the millisecond range allows one to increase the current, ultrashort pulses allows one also to affect the electron energy distribution. This was demonstrated by recording the electron density and the excimer emission in nanosecondpulsed discharges in a geometry similar to that shown in Figure 12b. By superimposing 10 ns pulses to a dc microdischarge, the electron density could be increased from $10^{15} \mathrm{~cm}^{-3}$ to $5 \times 10^{16} \mathrm{~cm}^{-3}$. Figure 20 shows a $10 \mathrm{~ns}$ pulse superimposed to the dc discharge sustained at $150 \mathrm{~V}$, with the resulting temporal development of the excimer radiation pulse [68]. The strong increase in electron density and the correlated increase in VUV radiation by more than an order of magnitude over that obtained with dc discharges is due to pulsed electron heating [69]. As with millisecond discharges, the application of a nanosecond pulse with an amplitude exceeding the dc voltage by up to an order of magnitude on top of the dc voltage, the plasma layer expands for a short time from the microhole in the center (insert) over a large part of the cathode surface outside the hole, forming a normal glow on this surface.

A study of the dependence of the Xe excimer emission in ns-pulsed MHC discharges on the pulse duration showed that shorter pulses do not necessarily lead to higher excimer emission intensity [70]. Using a similar concept as described by Moselhy et al. [68], by superimposing a nspulse of $1.5 \mathrm{kV}$ amplitude to a low-current dc MHC discharge, it was shown that the emission intensity increased by an order of magnitude when the pulse duration was increased from 20 to 100 ns (Fig. 21). Increasing the pulse duration to $1 \mu \mathrm{s}$ did not cause a further rise in excimer emission. This was assumed to be due to the increased gas heating for pulse durations exceeding the electron relaxation time.

Operating $\mathrm{MHC}$ discharges in Ar at high repetition rates $(1 \mathrm{MHz})$ with pulse duration of $80 \mathrm{~ns}$ and amplitudes of nearly $300 \mathrm{~V}$ did not generate Ar excimer radiation [71]. This was assumed to be due to gas heating, which for multiple discharges at high repetition rates is a cumulative effect and leads to a glow-to-arc transition. However, in $\mathrm{Ar}-\mathrm{H}_{2}$ mixtures, Lyman- $\alpha$ emission at $121.6 \mathrm{~nm}$ was observed with an optical power of $3.4 \mathrm{~W}$ at an efficiency of $0.63 \%$. 


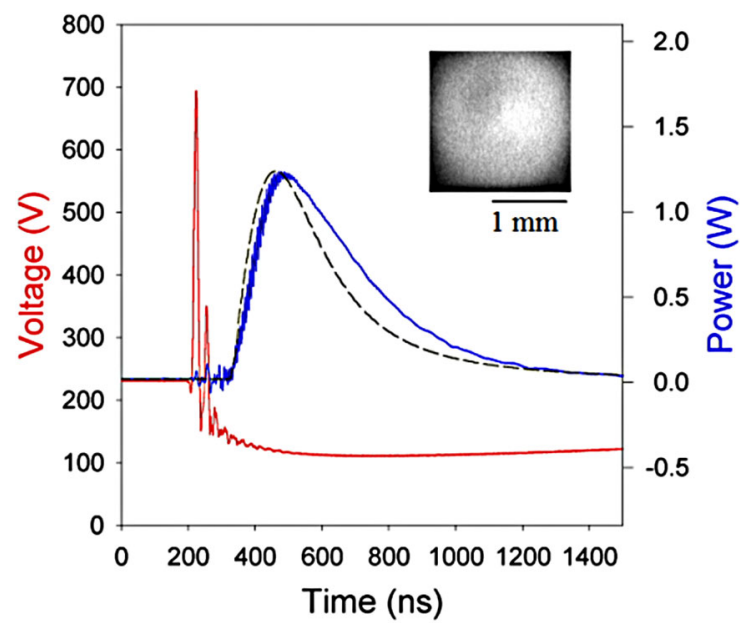

Fig. 20. Temporal development of the voltage across the MHC discharge and the corresponding Xe excimer emission. The voltage before pulse application is the sustaining voltage of the dc discharge. After pulse application, the discharge voltage drops to $110 \mathrm{~V}$ and approaches the dc value of about $230 \mathrm{~V}$ after several microseconds. The solid line represents the temporal development of the excimer emission. The dc value of the excimer power (indicated by DC) is less than $2 \%$ of its peak power. The dashed lines represents modeling results. The insert shows an image of the excimer source with a $100 \mu \mathrm{m}$ hollow located in the center [68].

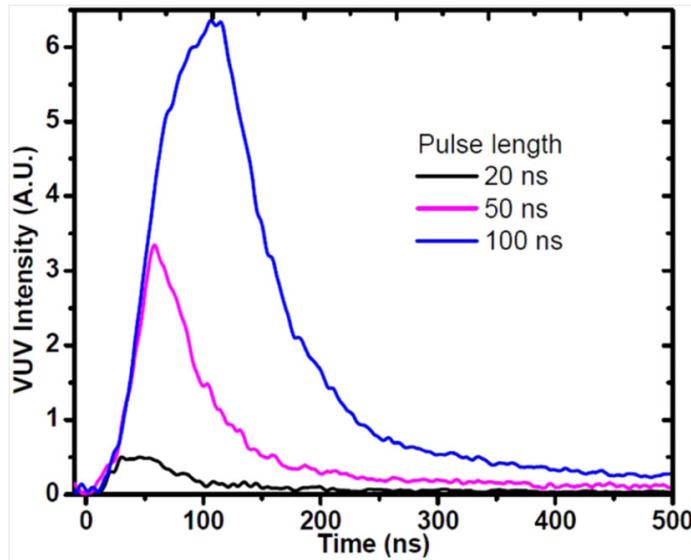

Fig. 21. Temporal development of VUV emission intensity from the MHC discharge in 800 mbar Xe at different high voltage pulses [70].

\subsection{Capillary plasma electrode (CPE) discharges}

The configuration of the capillary plasma electrode (CPE) discharge (see Fig. 22) looks very similar to that of a dielectric barrier discharge (DBD). However, its basic properties and operating principle are quite different. The basis for the atmospheric-pressure operation of the $\mathrm{CPE}$ discharge is a novel electrode design [72]. This design uses dielectric capillaries that cover one or both electrodes of a discharge device. The CPE discharge exhibits a mode of operation that is not observed in a DBD, the so-called "capillary jet mode". Capillaries with diameters from 0.01 to $1 \mathrm{~mm}$ and length-to-diameter ratios of about

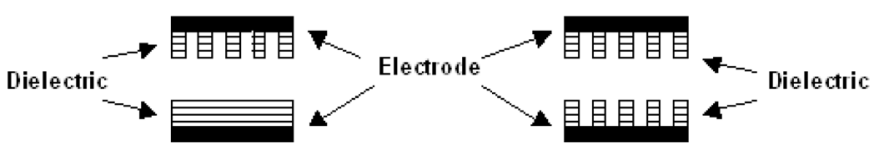

Fig. 22. Schematic diagram of a capillary plasma electrode (CPE) discharge with either one or two perforated dielectrics [72].

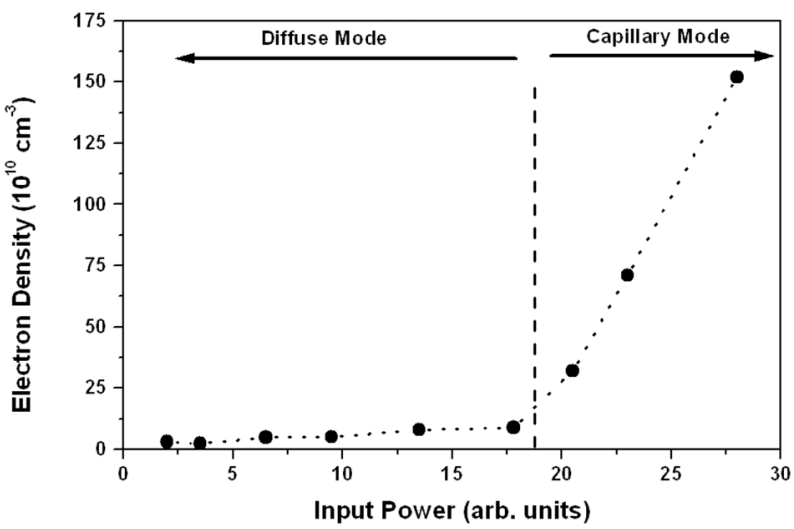

Fig. 23. Electron density in a He CPE discharge as a function of power input. The transition of the discharge from the diffuse to the capillary mode with a concurrent drastic increase in the electron density is clearly apparent [72].

10:1 serve as plasma sources, which produce jets of highintensity plasma at atmospheric pressure under certain operating conditions. The plasma jets emerge from the end of the capillary and form a "plasma electrode" for the main plasma and a stable uniform discharge can be achieved for the right capillary geometry, dielectric material, and exciting electric field. The placement of the tubular dielectric capillary(s) in front of the electrode(s) is crucial for the "capillary jet mode". The CPE discharge displays two distinct modes of operation when excited by pulsed dc or ac, a diffuse mode below a critical frequency and a mode above that frequency where the capillaries "turn on" and a bright, intense plasma jet emerges from the capillaries. This transition is manifested in a drastic increase in the electron density as shown in Figure 23. When many capillaries are placed in close proximity to each other, the emerging plasma jets overlap and the discharge appears uniform. This "capillary" mode has been characterized in a rudimentary way for several laboratory-scale research discharge devices in terms of its characteristic electric and other properties [73,74]: peak discharge currents of up to $2 \mathrm{~A}$, current density of up to $80 \mathrm{~mA} / \mathrm{cm}^{2}, E / p$ of about $0.25 \mathrm{~V} /(\mathrm{cm}$ Torr), electron density $n_{\mathrm{e}}$ above $10^{12} \mathrm{~cm}^{-3}$, power density of about $1.5 \mathrm{~W} / \mathrm{cm}^{3}$ in He and up to $20 \mathrm{~W} / \mathrm{cm}^{3}$ in air.

Using a Monte Carlo modeling code, a relatively high average electron energy around $5 \mathrm{eV}$ as well as the existence of the critical frequency were verified [73]. CPE discharges can operate at atmospheric-pressure in $\mathrm{He}, \mathrm{Ar}$, $\mathrm{He}-\mathrm{N}_{2}$, He-Air, He- $\mathrm{H}_{2} \mathrm{O}, \mathrm{N}_{2}-\mathrm{H}_{2} \mathrm{O}$, and air- $\mathrm{H}_{2} \mathrm{O}$ gases and gas mixtures and discharge volumes of more than $100 \mathrm{~cm}^{3}$. While a full understanding of the fundamental processes in the CPE discharge on a microscopic scale has not been 

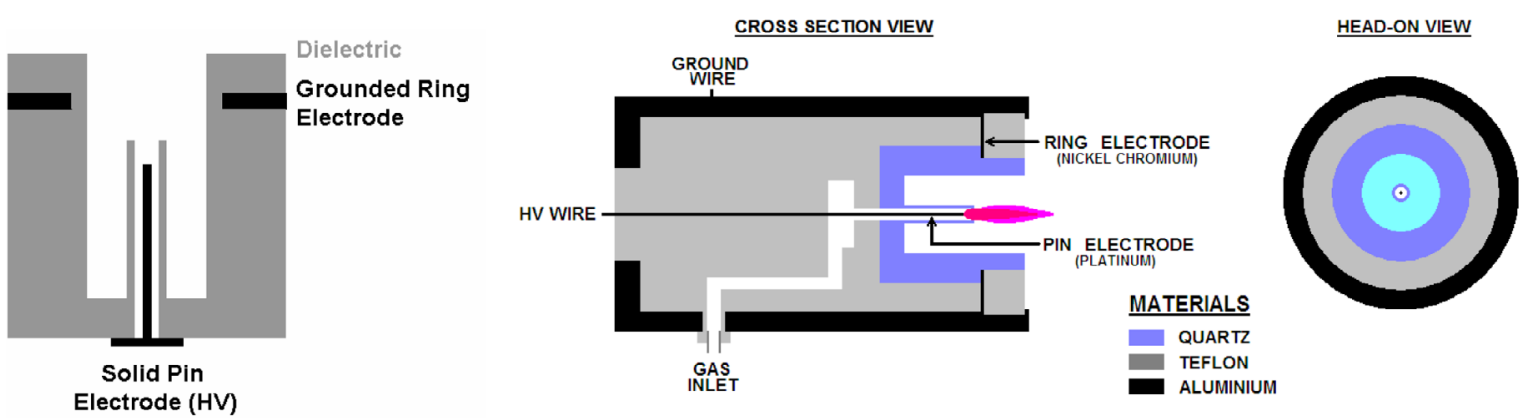

Fig. 24. Pin-type CPE discharge devices, no external gas flow (left), flow-through (right) [72]. The solid pin electrode has a diameter of $0.05 \mathrm{~mm}$ and is recessed by about $2 \mathrm{~mm}$ inside a dielectric tube of $0.2 \mathrm{~mm}$ inner diameter. The grounded ring electrode is about $1 \mathrm{~mm}$ above the top of the dielectric capillary.

achieved, it appears that the capillaries act as individual high-density plasma sources. The initial step is the formation of a streamer-like discharge inside each capillary, whose properties are critically determined by their interaction with the dielectric walls of the capillaries.

Further studies were carried out with two pin CPE discharge configurations, one with no external gas flow (shown in Fig. 24 on the left) and one flow-through device (shown in Fig. 24 on the right) [74]. The pin CPE without external gas flow has three easily distinguishable modes of operation. At low power, the visible part of the discharge is essentially confined to an area close to the pin and stays completely inside the surrounding capillary (mode 1). With increasing power, the discharge emerges from the capillary and is pushed out (mode 2 and preferred mode of operation). If the power is increased further, random filamentary discharges (streamers) appear between the pin and the grounded electrode, which is imbedded in a dielectric (mode 3 ). We note that in the presence of an external gas flow through the device, modes 1 and 2 are essentially indistinguishable visually. Figure 25 shows the current-voltage characteristic of a pin CPE discharge without external gas flow. The two sets of arrows indicate the transition from modes 1-2 (lower arrows) and modes 2-3 (upper arrows), respectively.

The curve is essentially linear and the visually prominent transitions from one mode of operation to another are not reflected in the current-voltage characteristic.

\subsection{Micro-hollow cathode sustained discharges}

By placing a third electrode on the anode side of a $\mathrm{MHC}$ discharge structure, it is possible to extend atmosphericpressure plasmas beyond the microhole [75]. These discharges, where an MHC discharge acts as a plasma cathode, were named micro-hollow cathode sustained (MHCS) discharges [76]. Since the electrons for the discharge outside the MHC geometry are now provided by the MHC discharge, instabilities emerging from the cathode fall of a planar cathode are avoided, and stable, large(r) volume high pressure discharges can be generated this way. An example is shown in Figures 26a and 26b [75]. Small vari-

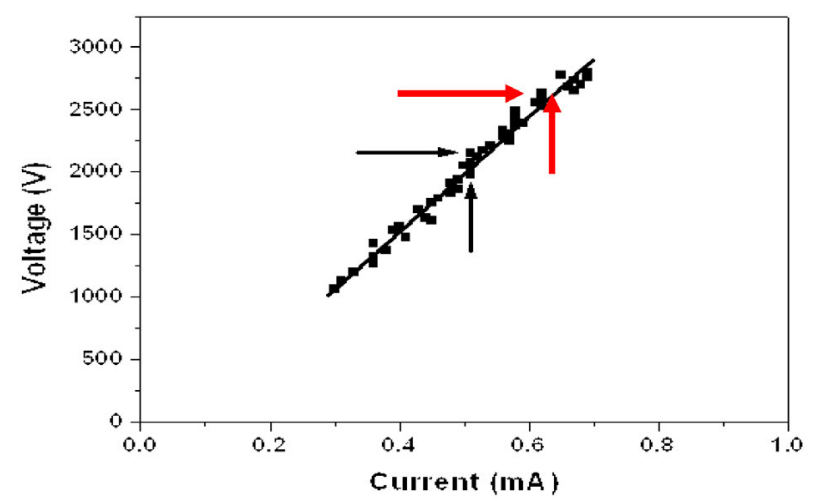

Fig. 25. Current-voltage $(I-V)$ characteristic of the pin CPE discharge without external gas flow. The lower arrow indicates the transition from modes 1-2 and the upper arrow indicates the transition to the 3rd mode of operation [72].

ations in the microcavity discharge voltage cause large changes in the microcavity discharge current and consequently in the current to the third, external electrode. This method allowed not only the generation of larger atmospheric pressure discharges in noble gases but also in molecular gases, such as air [76] as shown in Figure 26c [77].

\section{Plasma parameters of high pressure microdischarges}

The most important parameters of microdischarges are gas temperature, electron density and electron energy, or electron energy distribution, respectively. Depending on the application, there are measurements of other plasma parameters such as concentration of species in certain excited states, but in this review, we will focus on the three plasma parameters mentioned above. Because of the size of these plasmas mainly optical diagnostic methods have been used that include emission and absorption spectroscopy as well as interferometry, and Thomson and Rayleigh scattering. 

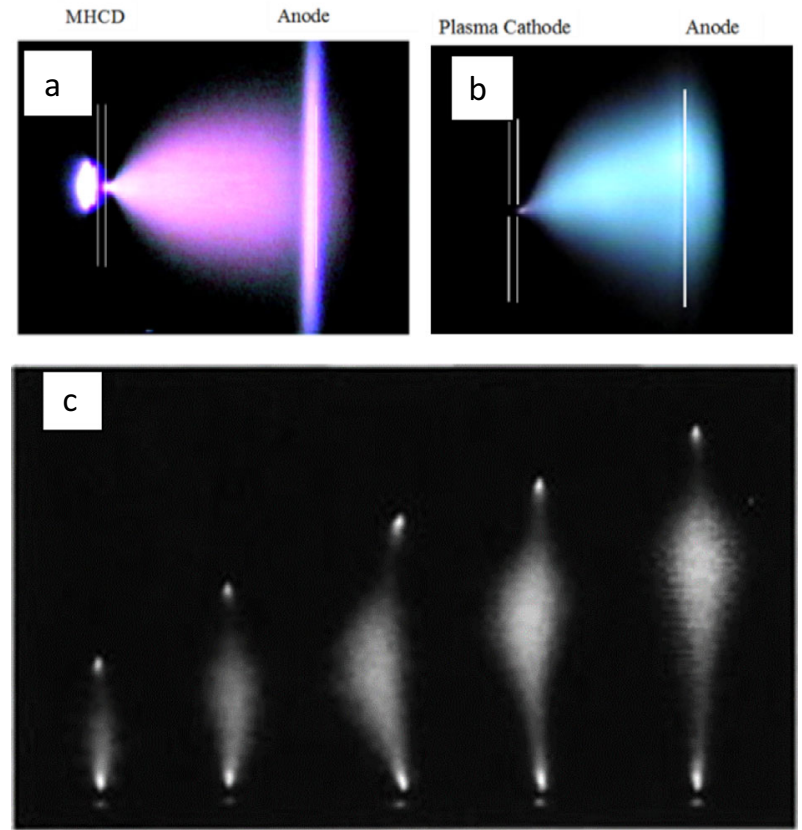

Fig. 26. MHCS discharges in Ar at (a) 160 Torr, (b) 760 Torr. The gap between MHC discharge and third electrode was $5 \mathrm{~mm}$ [75]. (c) Atmospheric-pressure air glow discharges with gap lengths ranging from 0.5 to $2 \mathrm{~cm}$. The current was kept constant at $13 \mathrm{~mA}$ [77].

\subsection{Gas temperature}

A frequently used method to determine the gas temperature in gases mixtures, which either already contain $\mathrm{N}_{2}$ (air) or where the plasma parameters are not affected by small additives of $\mathrm{N}_{2}$, is based on the measurement of the spectrum of the second positive band of $\mathrm{N}_{2}$, and its comparison to a modeled spectrum. For a MHC discharge in atmospheric-pressure air, the temperature obtained with this diagnostic method rises from $1700 \mathrm{~K}$ to $2000 \mathrm{~K}$ when the current is increased from $4 \mathrm{~mA}$ to $12 \mathrm{~mA}$ [78]. For atmospheric-pressure air microdischarges between parallel electrodes, the rotational temperatures varied between 700 and $1550 \mathrm{~K}$ for current of 4 and $10 \mathrm{~mA}$, respectively [31]. Measurements of a microwave-sustained plasma in atmospheric-pressure air in a $25 \mu \mathrm{m}$ wide discharge gap, using the same diagnostic method, provided rotational temperatures ranging between 500 and $700 \mathrm{~K}$ [79].

The temperature in microdischarges operating in noble gases and/or at lower pressure is considerably lower. Using the second positive system of $\mathrm{N}_{2}$, the rotational temperature for a 400 Torr Ne MHC discharge at $1 \mathrm{~mA}$ was determined to be approximately $400 \mathrm{~K}$, and increasing with discharge current [80]. Similarly, the rotational temperature measured in $\mathrm{Ar}+\mathrm{N}_{2}(0.1 \%)$ was found to be $400 \mathrm{~K}$ at $1 \mathrm{~W}$ microwave power [81]. These low temperature data for noble gas operation are consistent with results obtained with absorption spectroscopy [48]. The gas temperature in MSE-arrays in Ar at pressures ranging from 38 to 300 Torr was derived from the Doppler broadening of Ar lines in the near infrared. The gas temperature was found to increase with pressure from $380 \mathrm{~K}$ to $1100 \mathrm{~K}$ at a constant discharge current of $0.5 \mathrm{~mA}$.

Another diagnostic method is Rayleigh scattering, which has been used to determine the gas temperature of a $3 \mathrm{~mm}$ long atmospheric-pressure dc-excited glow discharge in air with a water electrode [82]. At a current of $15 \mathrm{~mA}$, the gas temperature in the positive column obtained from Rayleigh scattering was $2600 \pm 100 \mathrm{~K}$. This temperature was almost identical to that obtained with calculated rotational temperatures measured by optical emission spectroscopy of $\mathrm{N}_{2}(\mathrm{C})$. The results were compared to those obtained from the emission of the hydroxyl $\mathrm{OH}(\mathrm{A})$. It was found that the $\mathrm{OH}(\mathrm{A})$ emission measurements did not provide reliable results, presumably because of quenching processes of the excited state.

The results show that the gas temperature depends strongly on the type of operating gas and pressure: the highest values of more than $2000 \mathrm{~K}$ were obtained in atmospheric-pressure $\mathrm{MHC}$ discharges in air, while the lowest values, close to room temperature, were observed in noble gases at pressures below 100 mbar. The temperature typically increases with discharge current. Thus, for noble gas discharges at relatively low pressure and low current, the microdischarge plasma is "cold", with gas temperatures approaching values close to room temperature.

\subsection{Electron density}

Most of the methods used to measure the electron densities in microhollow cathode discharges are based on emission spectroscopy. In Ar, the electron density was measured using either Stark broadening of the hydrogen Balmer- $\beta$ line at $486.1 \mathrm{~nm}$ [83] or Stark broadening and shift of Ar lines in the near infrared [48]. In both cases, the electron densities for dc microdischarges were on the order of $10^{15} \mathrm{~cm}^{-3}$. Measured electron densities in a dc MHC discharge in atmospheric-pressure Ar with a small admixture of $\mathrm{H}_{2}$ are shown in Figure 27 [83]. The electron density increases slightly with the discharge current, and exceeds values of $10^{15} \mathrm{~cm}^{-3}$ for a dc discharge current of $4 \mathrm{~mA}$.

When operated in the pulsed mode, applying 10 ns electrical pulses of $600 \mathrm{~V}$, the electron densities increased to $5 \times 10^{16} \mathrm{~cm}^{-3}$ [83]. Even higher electron densities have been measured in an atmospheric-pressure Ar microdischarge between two cylindrical electrodes separated by a gap of $160 \mu \mathrm{m}$. Based on the Stark broadening of the $4 p$ - $4 \mathrm{~s}$ Ar line at $696.54 \mathrm{~nm}$, the maximum electron density was found to exceed $10^{17} \mathrm{~cm}^{-3}$, when $3 \mathrm{~ns}$ pulses of $2.46 \mathrm{kV}$ amplitude were applied [84].

For microdischarges between plane parallel electrodes the electron densities do not seem to reach quite the same values obtained in microcavity discharges. Using Thomson scattering as a means to determine the electron density in a Ar microdischarge with a $600 \mu \mathrm{m}$ gap, the electron density was found to be $6( \pm 3) \times 10^{13} \mathrm{~cm}^{-3}$ for a $50 \mathrm{~mA}$ microdischarge in a pressure range of 300 to 700 Torr [85]. 

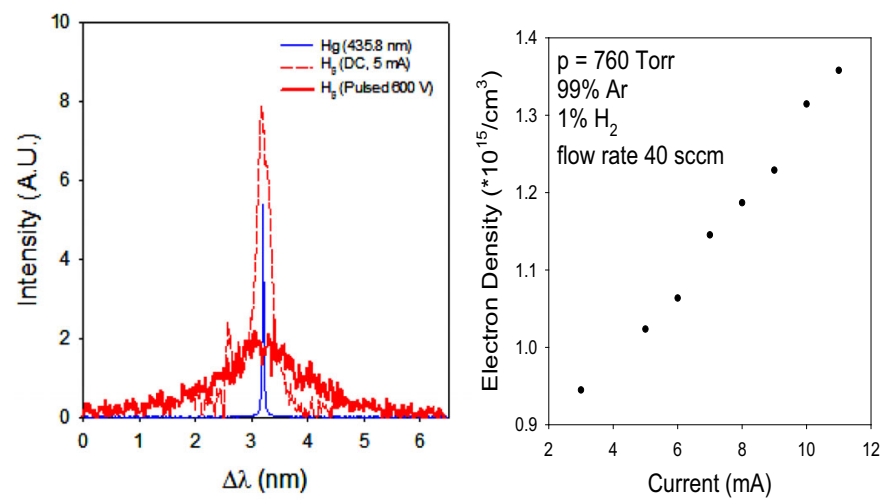

Fig. 27. Left: stark-broadened profile of the Balmer $\mathrm{H}_{\beta}$ line at $486.1 \mathrm{~nm}$ for dc and pulsed (10 ns) operation. Also shown is the apparatus profile using the $\mathrm{Hg} 435.8 \mathrm{~nm}$ line. Right: electron density of a $1 \mathrm{~atm} d c$ Ar MHC discharge vs. discharge current [83].

Electron densities in MHC discharges in atmosphericpressure air have also been measured using heterodyne infrared interferometry [86]. In a MHC discharge with a hole diameter of $200 \mu \mathrm{m}$ and a current of $12 \mathrm{~mA}$ at a voltage of $380 \mathrm{~V}$, the electron density in atmospheric-pressure air was $10^{16} \mathrm{~cm}^{-3}[78]$. The electron density in atmosphericpressure MHCS discharges is considerably lower. On the axis of the MHCS discharge it was found to be $10^{13} \mathrm{~cm}^{-3}$, three orders of magnitude lower that that measured inside the MHC discharge [86].

Electron densities in microwave-sustained discharges in atmospheric-pressure $\mathrm{Ar}$ are in the range from $10^{14}$ to $10^{15} \mathrm{~cm}^{-3}$. For transmission line microplasmas, where the transmission line has an impedance of $50 \Omega$, the electron density must be on the order of $10^{15} \mathrm{~cm}^{-3}$ in a matched circuit, a value which was confirmed by electron density measurements based on the Stark broadening of the $\mathrm{H}_{\beta}$ line emission at $486.1 \mathrm{~nm}$ [87]. For microwave discharges generated in a resonator circuit [12], the electron density is limited to approximately $10^{14} \mathrm{~cm}^{-3}$ for optimum power coupling, a value which was confirmed by measurements in a split-ring resonator microplasma, again using Stark broadening of the of the $\mathrm{H}_{\beta}$ line [87].

Typically, the electron densities in dc microcavity discharges and in microwave transmission line discharges are on the order of $10^{15} \mathrm{~cm}^{-3}$. In microwave resonator discharges, they are lower, about $10^{14} \mathrm{~cm}^{-3}$. Even lower are the electron densities in dc discharge plasmas between plane parallel electrodes and in dc MHCS discharge plasmas with values generally in the range of $10^{13}$ to $10^{14} \mathrm{~cm}^{-3}$. However, if pulsed with nanosecond pulses either superimposed to the dc discharge or independent of it, electron densities of up to $10^{17} \mathrm{~cm}^{-3}$ have be reported.

\subsection{Electron temperature-electron energy distribution}

Electron temperatures have been measured using optical emission spectroscopy (line ratio techniques) and Thomson scattering. Using line intensity measurements

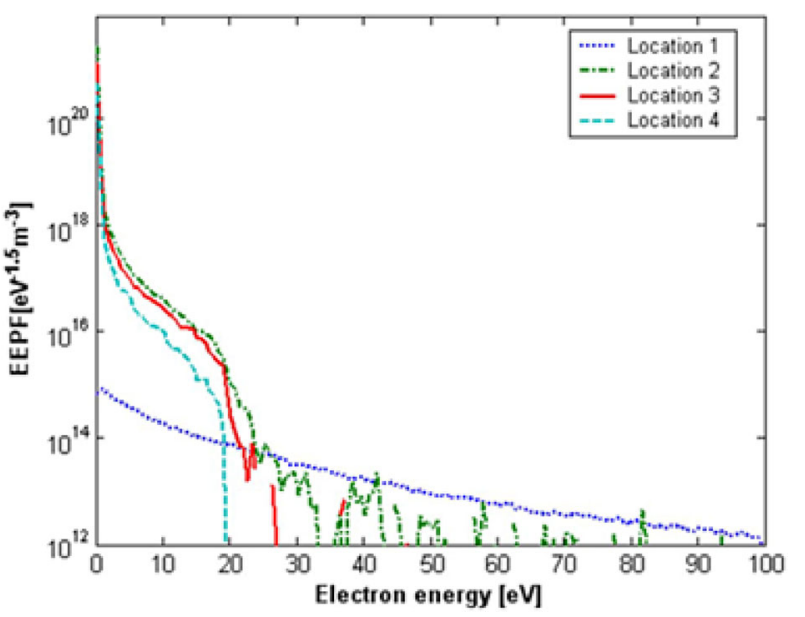

Fig. 28. Electron energy distribution function at various locations in a dc He microdischarge operated at atmospheric pressure. Locations $1-4$ correspond to $x=20,58,83$, and $136 \mu \mathrm{m}$ from the planar cathode [91].

and assuming a Boltzmann distribution of the population of the excited states, the electron temperature in dc MHC discharges in Ar was found to be on the order of $1 \mathrm{eV}$ [88]. For pulsed Ar discharges, the electron temperature was found to rise to about $2.5 \mathrm{eV}$ several microseconds after the 3 ns pulse was applied [84]. The authors explain this phenomenon by the relatively long exposure time of the iCCD camera which was used to record the temporal development of the line intensities, and which caused them possibly to miss the peak electron temperature right at the time of the $3 \mathrm{~ns}$ pulse. The rise of the electron density for a few microseconds after the pulses was attributed to temporal changes in the repopulation mechanism. Using Thomson scattering as a means to determine the electron temperature in Ar discharges between plane parallel electrodes an electron temperature on the order of $1 \mathrm{eV}$ was measured [85].

However, since the electron energy distribution is highly non-Maxwellian (the discharge is, to a large extent, determined by the processes in the cathode fall and negative glow), it is expected that there is a large concentration of electrons with energies up to the cathode fall energy (beam electrons). The importance of beam electrons has been proven through modeling [89-91].

Electron energy probability functions were obtained by means of particle-in-cell Monte Carlo collision models. The electron and ion kinetics in an atmospheric-pressure He microdischarge between parallel plate electrodes with a $200 \mu \mathrm{m}$ gap are shown in Figure 28 for various locations from the cathode [91]. The discharge current density was fixed at $1 \mathrm{~A} / \mathrm{cm}^{2}$. Near the cathode, the electron energy distribution contains a high concentration of energetic electrons with energies above $20 \mathrm{eV}$. This is due to the strong acceleration of electrons in the cathode fall. As electrons reach distances larger than the energy relaxation length of approximately $10 \mu \mathrm{m}$, the high energy tail disappears with the electron energy distribution approaching a bi-Maxwellian shape. 


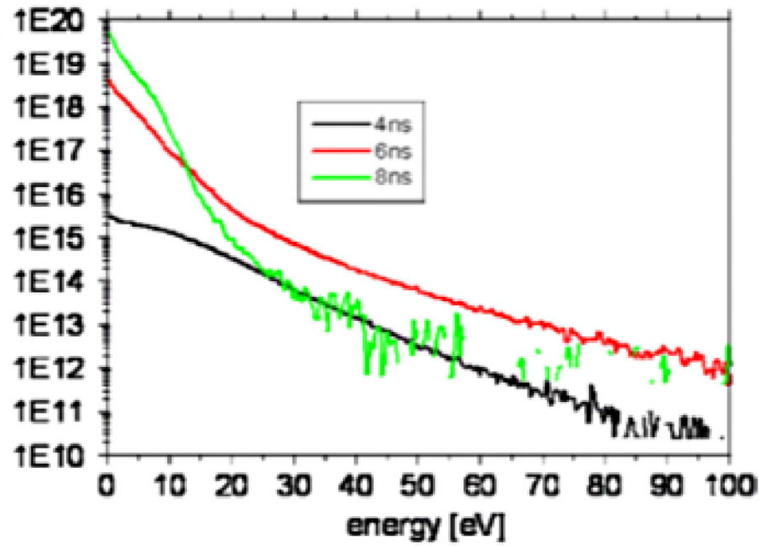

Fig. 29. The electron energy distribution function for an Ar MHC discharge at 300 Torr, $0.1 \mathrm{~mA}$, at $4 \mathrm{~ns}, 6 \mathrm{~ns}$, and $8 \mathrm{~ns}$ [90].

In another modeling study, again using a particle-incell Monte Carlo approach, the electron and ion kinetics in a 300 Torr Ar discharge in a microhollow cathode geometry (radius of the cathode hollow: $50 \mu \mathrm{m}$ ) and the development of the electron energy distribution in the ignition phase was studied. This phase which in this study was on the order of nanoseconds, describes well the changes in the electron energy distribution of a $10 \mathrm{~ns}$ pulsed discharge [90]. Figure 29 shows the electron energy probability function (EEPF) at 4, 6, and 8 ns after ignition. At $4 \mathrm{~ns}$, the distribution function is of a Druyvesteyn form. As electrons drift towards the anode, the low energy part of the EEPF is populated by electrons generated by electron collision, generating a bi-Maxwellian distribution. Later in time, at $8 \mathrm{~ns}$, the cathode fall region is established. As a result, the electron temperature of the low energy electrons decreases to values of approximately $1.5 \mathrm{eV}$, but the high energy tail persists.

Until recently, measurements of electron energy distributions in microdischarges have not been reported. However, Thomson scattering has now made is possible to obtain the electron energy distribution in a microdischarge in a range of energies up to $12 \mathrm{eV}$ [92]. Such measurements were performed in a $\mathrm{He}$ microdischarge between planar molybdenum electrodes separated by a gap of $0.95 \mathrm{~mm}$. The microdischarge was generated by means of $150 \mathrm{~ns}$ pulses with amplitudes of 1 to $2 \mathrm{kV}$. Figure 30 shows the electron energy distribution at 120 ns. It is Maxwellian, corresponding to an electron temperature of $3.5 \mathrm{eV}$ for this point in time. The measured Maxwellian distribution for this range of electron energies $(<12 \mathrm{eV})$ is consistent with modeling results in the same energy range, which was obtained also for a He discharge in a similar discharge geometry, however operated in a dc mode (see Fig. 28) [91]. The deviations from a single Maxwellian function, i.e. the predicted bi-Maxwellian structure, appears only when the electron energy range is extended to higher energies, as indicated by modeling studies on pulsed MHC discharges in Ar at 300 Torr (Fig. 29).

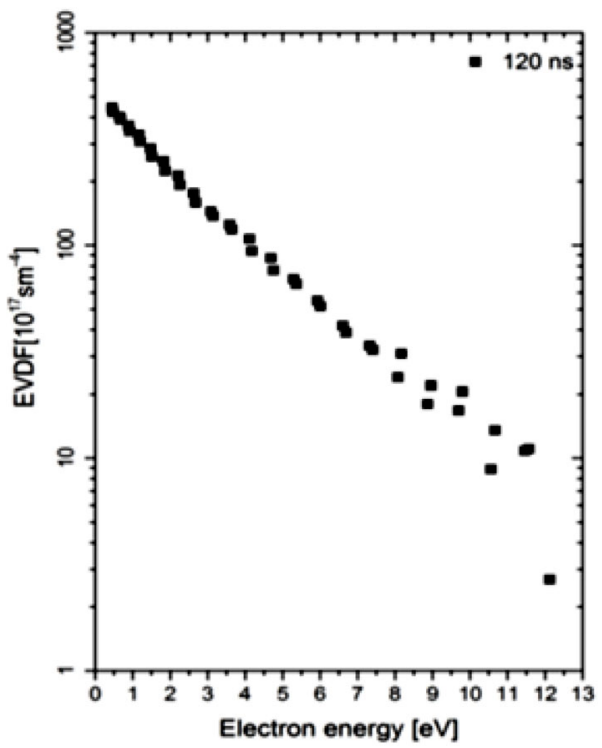

Fig. 30. Electron energy distribution at $120 \mathrm{~ns}$ in a $150 \mathrm{~ns}$ pulsed atmopheric pressure He plasma between two planar electrodes with a $0.95 \mathrm{~mm}$ gap (courtesy of U. Czarnetzki, Ruhr-Universität Bochum).

\section{Plasma jets}

Atmospheric-pressure plasma sources, which generate plasma in open space rather than in spatially confined discharge gaps, so-called "atmospheric-pressure plasma jets (APPJs)", were first developed about 15 years ago and have gained much prominence in the past 10 years. The need for such sources was largely driven by applications, by the need for plasma treatment of objects, whose size and shape did not allow them to be placed in the discharge gaps for direct place treatment. The conventional sources also pose a challenge for indirect (remote) plasma treatment, where the object is placed downstream because of the short lifetime of reactive plasma radicals and charged particles, particularly at atmospheric pressure, where the electron - heavy particle collision frequency is high. Thus, the concentration of species most effective for the plasma treatment is significantly reduced when the species reach the object, which renders the plasma treatment ineffective. Moreover, when the plasma is to be sustained in open space, one faces the additional challenge that the applied electric field is typically too low to sustain the plasma. Different methods were developed to address these challenges and a number of APPJ concepts have been realized and are in use. A recent review [10], which is an extension of an earlier paper [93], provides an excellent summary of the various APPJs and their operational characteristics. Other notable summaries of APPJs include two reviews $[94,95]$ and more information can be found in other publications [96-101].

While most APPjs operate with rare gases or rare gases with small admixtures of reactive gases, there are some APPJs that can operate in atmospheric-pressure ambient air without causing arcing. APPJs operating in rare gases fall into the categories of dielectric-free electrode (DFE) 


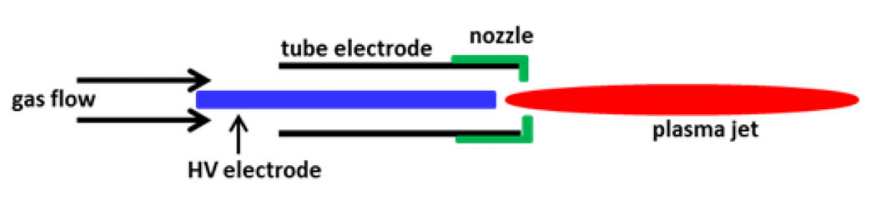

Fig. 31. Schematic diagram of a DFE jet.
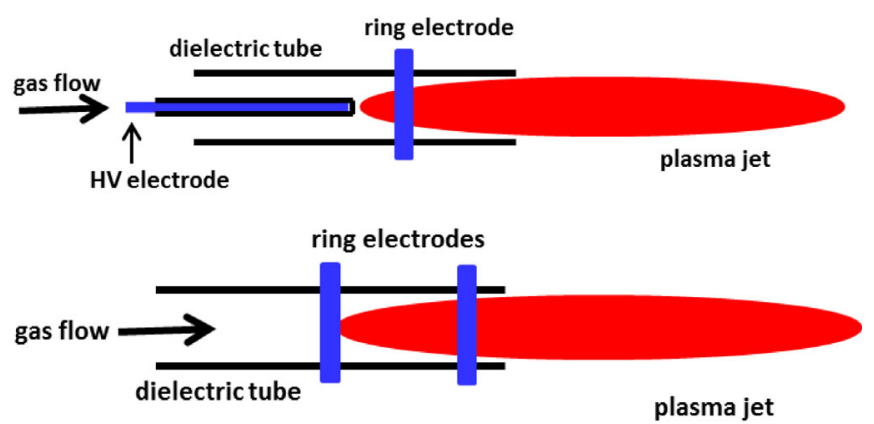

Fig. 32. Schematics of two typical DBD jets.

jets, dielectric barrier discharge (DBD) jets, DBD-like jets, or single electrode (SE) jets [10]. An early version of a DFE jet source, developed by Hicks and co-workers [102,103], is schematically shown in Figure 31. The DFE jet requires fairly high powers to generate the plasma, which, in turn, results in higher gas temperatures that make the jet unacceptable for most biomedical applications, yet suitable for many materials treatments that are not adversely affected by higher temperatures. Since the electric field in the discharge gap, and even more so in the plasma plume, is relatively weak, this plasma plume is gas-flow driven as opposed to electrically driven. Lastly, this jet has a tendency to arc except for a fairly narrow range of stable operating conditions. The preferred operating gas is He, sometimes with an admixture of a reactive gas.

The vast majority of APPJs are DBD or DBD-like jets and they come in many different designs and implementations. Two typical designs are shown in Figure 32. Figure 32 (top diagram) shows a jet generated inside a dielectric tube with two metal ring electrodes connected to a high-voltage AC power source operating typically in the $\mathrm{kHz}$ regime. When the operating gas flows through the tube, a cold plasma jet is ignited, which extends beyond the nozzle into the surrounding air. In the source shown in Figure 32 (bottom diagram), one of the ring electrodes is replaced by an insulated central pin electrode, which increases the electric field along the direction of the plasma plume and tends to lead to spatially elongated jets with high concentration of active species [10]. A variant of the source shown in the lower part of Figure 32 was used by Becker et al. as a source of intense vacuum ultraviolet radiation [104-106].

The Plasma Pipette, shown schematically in Figure 33 interacting with an extracted tooth, is a variant of the source shown in Figure 32 (top diagram) above, where one of the 2 ring electrodes has been removed. Here, the ring electrode is connected to a low frequency $(10 \mathrm{kHz})$

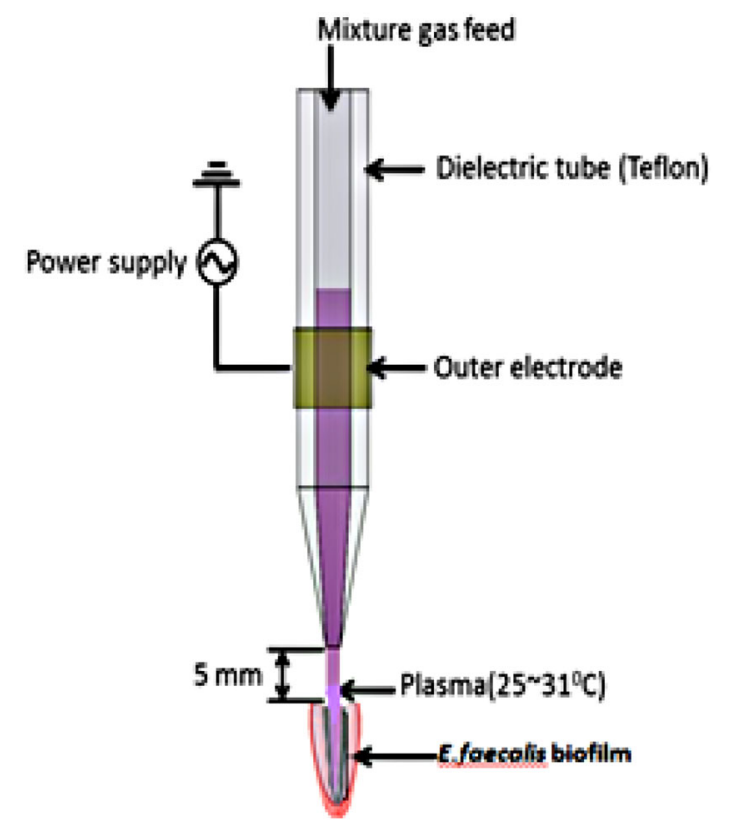

Fig. 33. Schematic diagram of the plasma pipette (PP) interacting with a biofilm covering an extracted tooth [100].

AC power supply (sinusoidal wave with a peak voltage of $18 \mathrm{kV}$ ) via a $1 \mathrm{M} \Omega$ ballast resistor. Various noble gases and noble gas with molecular gas admixed are used as the working gas. The plasma is generated inside the Teflon pipette tube near the powered electrode, and then propagates into open air, typically generating a plasma jet of up to $\sim 5 \mathrm{~cm}$ length. This source was used in a series of experiments aimed at the inactivation of dental biofilms and tooth whitening $[100,107,108]$.

The Plasma MicroJet (PMJ) device shown in Figure 34 (see e.g. [107]) is a slightly modified version of the source first described by Schoenbach et al. [97]. It is comprised of two copper tubings separated by an alumina tubing. The critical distance between the ends of the copper tubings is set to $\sim 0.5 \mathrm{~mm}$. An end cap with a circular opening ( $~ 0.8 \mathrm{~mm}$ in diameter, $\sim 1 \mathrm{~mm}$ in depth) is attached to the outer copper tubing to match the diameter of the pore on the inner copper tubing for optimal operation. The inner copper tubing is completely embedded in the device and powered by a dc power supply (negatively biased). The outer electrode is grounded. Compressed air or a rare gas with admixtures of a molecular gas (typically $\mathrm{O}_{2}$ ) is used as the working gas flow rate of $4-5$ standard liters per minute (slm). The sustaining voltage is in the range of 400-600 V with an operating current of 20-35 mA. The plasma jet is usually between $8-10 \mathrm{~mm}$ in length and has been used extensively in decontamination and biological inactivation studies (see e.g. [109]).

The so-called kINPen 09 source shown in Figure 35 [94,99], consists of a hand-held unit for the generation of a plasma jet at atmospheric pressure, a rf power supply, and a gas supply unit. It works with all rare gases (especially Ar), but also with $\mathrm{N}_{2}$ and air and admixtures of molecular gases to the rare gas. The plasma is ignited at the tip of a centered electrode inside a capillary and blown 


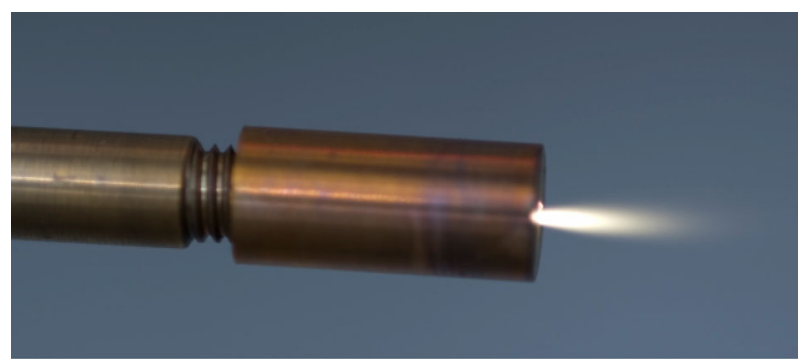

Fig. 34. Picture of the atmospheric-pressure cold PMJ [107].
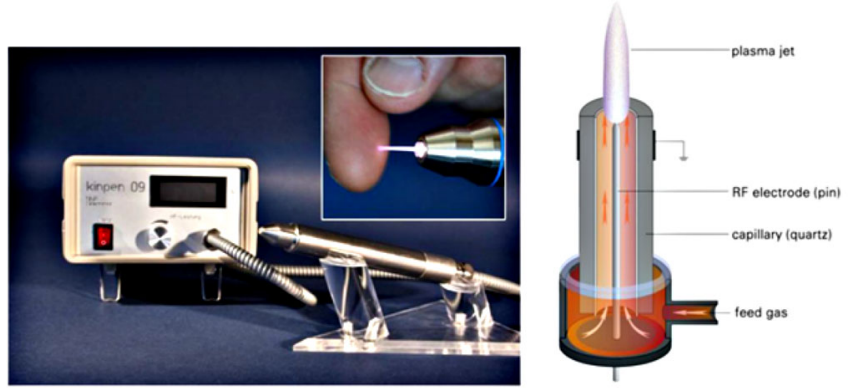

Fig. 35. Picture of INP kINPen 09 and a schematic diagram of the device (figure courtesy of INP Greifswald, Germany).

out by the gas flow to form the plasma jet. Because of the contracted plasma resulting from this type of generation, the kINPen 09 is especially suited for focused treatments of small spots. Large-scale treatments can be realized by moving the jet over a selected area. These features make it interesting for the treatment of parts of complex geometries and cavities, e.g. in operative dentistry or dermatology. If needed, plasma jets can also be arranged in arrays to adapt to specialized geometries.

It has been demonstrated [98] that APPJs generate copious amounts of reactive radicals. It has also been shown that these radicals exist outside the visible part of the plasma plume and can initiate plasma chemical reaction at significant distances away from the visible plasma plume. This is shown in Figure 36. Petri dishes of $9 \mathrm{~cm}$ in diameter were uniformly covered with either $E$. coli (Figs. 36a-36d) or M. luteus (Figs. 36e-36h) microorganisms. A small $2 \mathrm{~cm}$ by $2 \mathrm{~cm}$ square in the center was exposed to a PMJ source for a total treatment time of respectively $30 \mathrm{~s}, 60 \mathrm{~s}$, and $90 \mathrm{~s}$ (corresponding to a direct plasma exposure of each spot inside the square of $1.5 \mathrm{~s}$, $3 \mathrm{~s}$. and $4.5 \mathrm{~s}$ ). Note that the pictures (a) and (e) represent control groups that were not exposed to the plasma. Several observations are noteworthy:

- the inactivation is strongest in the area of direct plasma exposure;

- in both cases, inactivation also occurs outside of the region of direct plasma exposure, which indicates that plasma-generated reactive species are transported outside the region of direct plasma exposure and cause inactivation, albeit less effective than in the area of direct plasma exposure.

Two different inactivation patterns emerge. Figures 36b$36 \mathrm{~d}$ show a radially outward decreasing inactivation as the

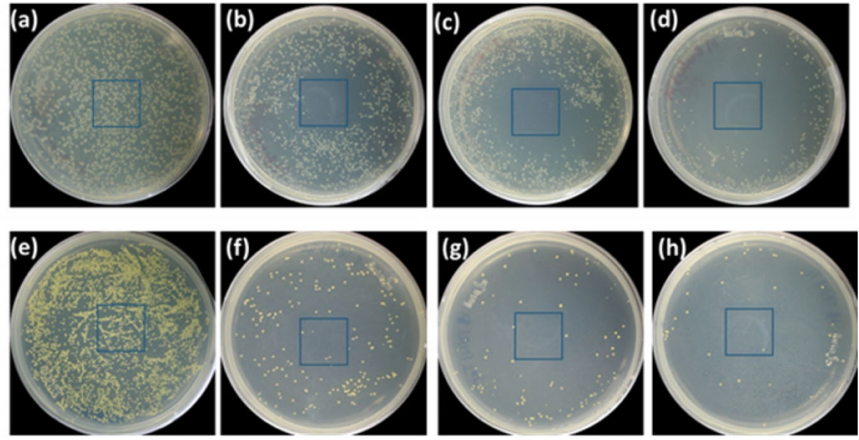

Fig. 36. Pictures to illustrate the different plasma inactivation effect on E. coli (a)-(d) and M. luteus (e)-(h) as a function of plasma exposure (see text for details) [98].

plasma treatment time increases, whereas Figures $36 \mathrm{f}-36 \mathrm{~h}$ are representative of an overall uniform inactivation, regardless of whether the microorganisms are directly exposed to the plasma jet or are subject to indirect (remote) plasma treatment. The different radial patters that emerge with increasing plasma exposure indicate that the plasma-initiated inactivation involves more than one reactive species and that synergies between the effect of various inactivation agents may play an important role.

The first reports of "plasma bullets" appeared in the literature in 2005 [110,111]. Shortly thereafter, Laroussi et al. [96] reported the generation of a "bullet-like" cold plasma plume traveling at unusually high velocities of more than $1 \times 10^{5} \mathrm{~m} / \mathrm{s}$, which is several orders of magnitude higher than the gas velocity. Figure 37 shows their source driven by pulsed dc voltage with pulse widths in the range of a few hundred nanoseconds and peak voltages around $5 \mathrm{kV}$. These pulses cause enhanced ionization and excitation.

\section{Microdischarge-arrays}

Although much of the research on microdischarges focuses on the physics of individual discharges, applications such as light sources, plasmas for material processing, and for therapeutic applications, require arrays of microdischarges. Two types of arrays, (i) microdischarges arranged in series and (ii) microdischarges arranged in parallel, are discussed in the following.

\subsection{Series operation of microcavity discharges}

Series operation of microdischarges is mainly of interest for light sources. Particularly for highpressure microdischarges in noble gases, where excimer radiation is generated [7] operating discharges in series allows increasing the intensity of VUV and UV radiation considerably. Since reabsorption of excimer radiation in the excimer gas is negligible, series operation of discharges allows an almost linear increase of excimer intensity with the number of discharges in series. This has been shown in experiments in a high-pressure gas mixture (1050 Torr) used for $\mathrm{XeCl}$ 


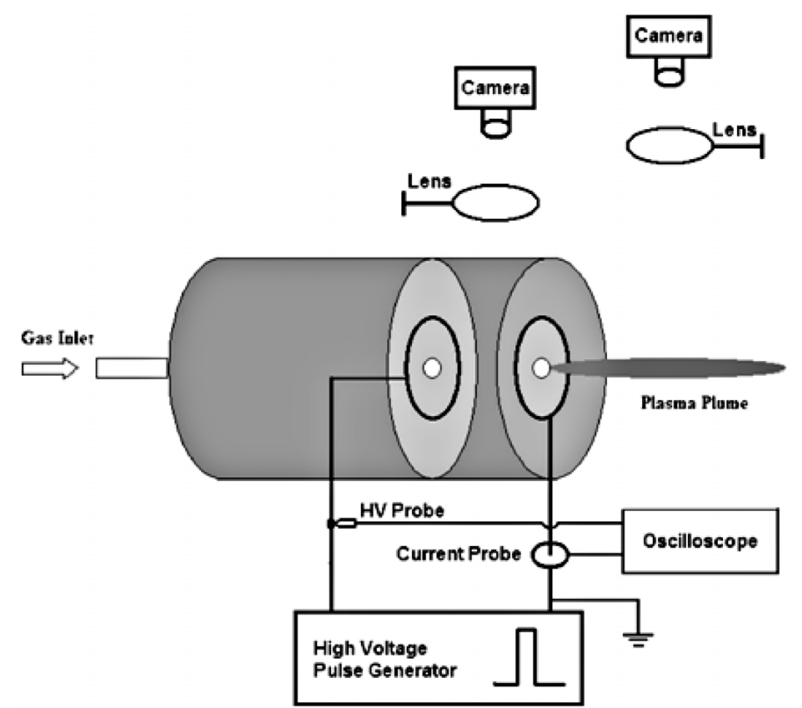

Fig. 37. Schematic diagram of a "plasma bullet" source [96]. The electrodes are made of a thin $\mathrm{Cu}$ ring attached to the surface of a centrally perforated alumina disk. The center hole in the $2.5 \mathrm{~cm}$ alumina disk is $3 \mathrm{~mm}$ in diameter. The electrodes are inserted in a dielectric cylindrical tube and separated by a $0.3-1 \mathrm{~cm}$ gap. The electrodes are connected to a HV pulse generator (pulses up to $10 \mathrm{kV}$, pulse widths from $200 \mathrm{~ns}$ to dc, repetition rate up to $10 \mathrm{kHz}$, and voltage rise and fall times of about $60 \mathrm{~ns})$.

excimer lasers. The first experiments of microdischarges in series were based on a tandem MHC discharge structure [112]. The $\mathrm{XeCl}$ excimer irradiance was doubled in this arrangement compared to a single discharge (Fig. 38). A ceramic structure with three microdischarge cells in series was successfully operated in Ne by Vojak et al. [113].

A simple estimate of the power density in a microdischarge indicated that these discharges may serve as an excimer laser medium [112]. The fact that optical gain can actually be achieved with microplasmas was demonstrated by Eden et al. [114]. In a discharge arrangement comprised of seven sets of microdischarges arranged optically in series with an overall active length of $\sim 1 \mathrm{~cm}$, indications of gain of the $460.30 \mathrm{~nm}$ emission of $\mathrm{Xe}^{+}$were observed. This marked the first example of a microdischarge-pumped optical amplifier. Research on the optical emission from microdischarges placed in series has been expanded in recent years from using classical MHC discharge geometries to using microtubes, which can be easier aligned [115]. An example is shown in Figure 39.

Three $5 \mathrm{~mm}$ long metallic capillary tubes with an inner diameter of $160 \mu \mathrm{m}$, separated by $400 \mu \mathrm{m}$ thick layers of sapphire insulators, were placed in series. Microdischarges in Xe were generated in a pressure range of 400-1013 mbar with a fixed flow rate of $100 \mathrm{sccm}$. The total sustaining voltage across the three discharges was about $700 \mathrm{~V}$, the current varied between 2 and $12 \mathrm{~mA}$. The measured irradiance of the triple discharges was found to be almost the sum of the irradiance of the individual discharges. This demonstrated again that series operation in noble gases allows a linear increase in irradiance by placing microcavity discharges in series.

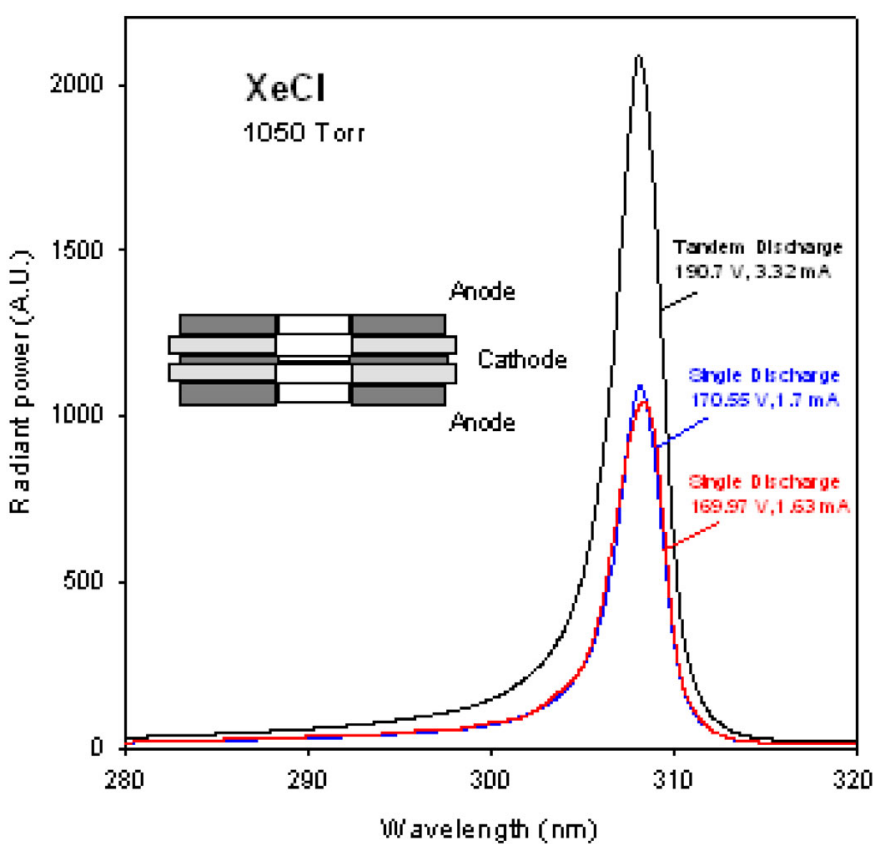

Fig. 38. Excimer spectra of single discharges between the center cathode and anode (1) (dotted line) and anode (2) dashed line, and the combined (tandem) discharge (solid line). The electrode configuration is shown in the inlet [112].

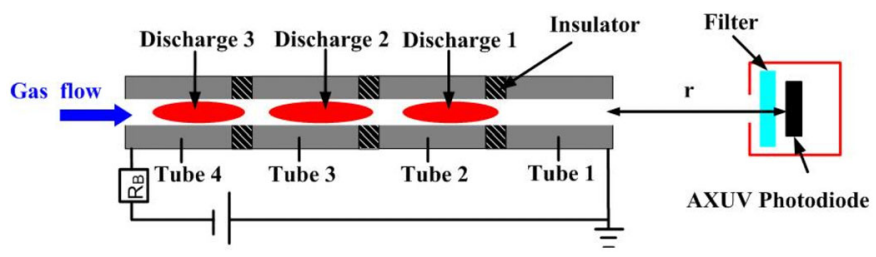

Fig. 39. Schematic of the triple capillary discharge set up [115].

It was shown that the use of ns pulses increased the excimer radiation by more than an order of magnitude compared to that obtained with de microdischarges [68]. This concept has been applied to a tandem MHC discharge configuration similar to that shown in Figure 38 (insert). The Xe excimer emission intensity from an 800 mbar Xe discharge pulsed with a $50 \mathrm{~ns}, 1.5 \mathrm{kV}$ pulse superimposed to a dc sustaining voltage of $270 \mathrm{~V}$ increased by almost two orders of magnitude above the value obtained for $\mathrm{dc}$ operation [117].

\subsection{Parallel operation of microdischarges}

Discharges operated in a current-voltage, $V-I$, range, where the $d V / d I$ is negative, which holds for microdischarge between plane parallel electrodes (Fig. 3) or for MHCS discharges, require individual ballasting when arranged in parallel. As an example, Figure 40 [116] shows an array of MHCS discharges in atmospheric-pressure air. MHC discharges at the root of the discharges serve as plasma cathodes and support the $8 \mathrm{~mm}$ long air discharges. In order to stabilize the discharges each carrying a current of $13 \mathrm{~mA}$, the individual discharges had to 


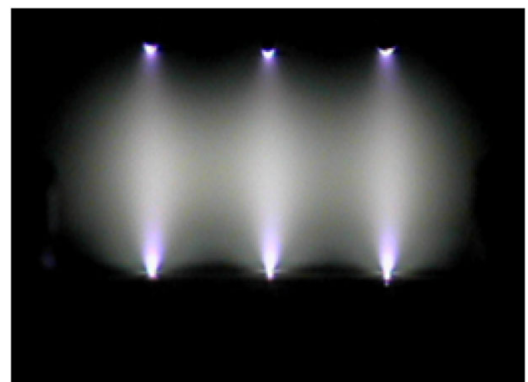

Fig. 40. Parallel operation of MHCS discharges in atmospheric pressure air stabilized by ballast resistors. The electrode gap is $8 \mathrm{~mm}[116]$.

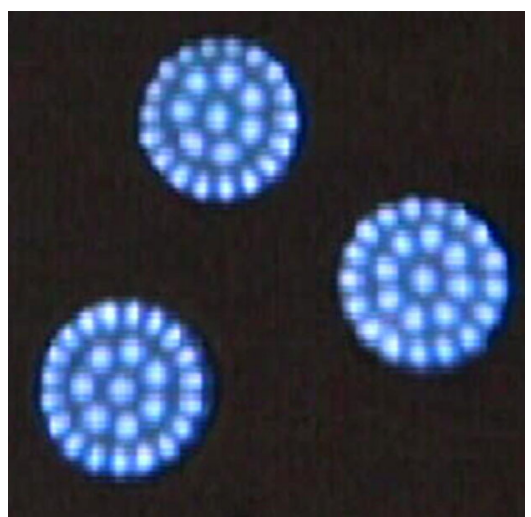

Fig. 41. Parallel operation of CBL discharges in three, $0.75 \mathrm{~mm}$ diameter, openings, using a single voltage source. The discharge voltage was $385 \mathrm{~V}$.

be connected to ballast resistors: the MHC discharge to a ballast resistor of $96 \mathrm{k} \Omega$, the MHCS discharge to a $210 \mathrm{k} \Omega$ resistor.

Microdischarges, such as cathode boundary layer discharges, which except for very low currents, show a positive $d V / d I$ over a wide range of pressures (Fig. 7) can therefore run in parallel without individual stabilization. Discharges with a positive slope of the voltage-current characteristic are, according to the Kaufmann criterion (Eq. (2)), inherently stable. An example is shown in Figure 41: three CBL discharges, each one operated in a selforganized mode, are sustained by a single current source without ballast resistor. Operating microdischarges in this mode allows one, therefore, to generate large area plasma arrays, which, for example, can be used as flat panel deep UV excimer radiation sources [118].

Microcavity discharges, such as the MHC discharge, have a positive $V-I$ characteristic at low currents (Figs. 14 and 15). In this current range, they can be placed in parallel without individual ballast [47], which allows the formation of flat panel plasma devices with a large number of discharges at high spatial density. Using Si technology, Eden and co-workers pioneered the development of larger and more complex arrays. Figure 42 shows one of their first microcavity arrays, with inverted pyramidal cathodes, operated in dc, and the corresponding $V-I$ characteristics for the discharges in Ne [57]. Subsequently, these researchers focused more on dielectric barrier structures, such as the

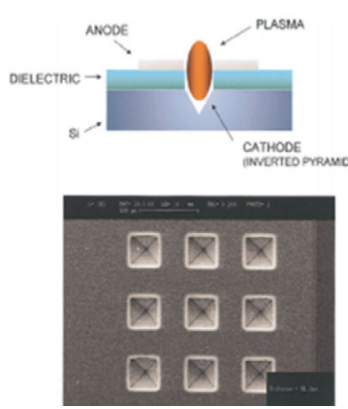

a

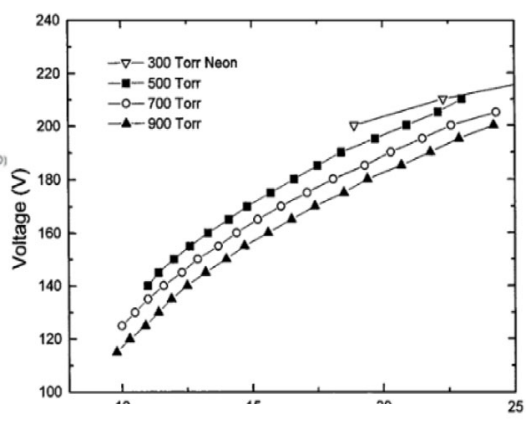

b
Fig. 42. (a) Top: generalized diagram of a Si pyramidal electrode microdischarge device. Bottom: scanning electron micrograph of a $3 \times 3$ array of microdischarge devices having inverted, square pyramidal cathodes fabricated in Si by photolithographic and wet chemical etching techniques. The dimensions of each microdischarge device at the Si surface are $50 \times 50 \mu \mathrm{m}$ and the dielectric is a composite, consisting of approximately $0.9 \mu \mathrm{m} \mathrm{SiO}_{2}$, approximately $0.5 \mu \mathrm{m} \mathrm{Si}_{3} \mathrm{~N}_{1}$, and $8 \mu \mathrm{m}$ of a dry etchable polyimide. (b) $V-I$ characteristics of discharges in Ne at verious pressure [57].

one shown in Figure 18, and significantly extended the number of parallel discharges. In 2006, arrays of microplasmas as large as $500 \times 500$ (250000 devices) had been developed, with all of the microplasmas driven in parallel by a $15 \mathrm{kHz}$ source. The uniformity of the emission from device-to-device over the entire array is one of the prominent characteristics of these Si device structures. A photograph of a segment of a $500 \times 500$ array of pyramidal microplasma devices operating in 700 Torr Ne is shown in Figure 43 [2].

Recently, replica molding [119] allowed to generate small microcavity displays that are flexible and transparent (see e.g. Fig. 44). The replica molding process enables arrays of microcavity plasma devices and connecting channels with feature sizes at least as small as $20 \mu \mathrm{m}$ to be produced inexpensively and precisely over surface areas of hundreds of square centimeters [9]. The efforts to fabricate less expensive displays led to the use of tape and paper as material. It was possible to sustain uniform discharge arrays in Ar and He for reasonably long times (Ar: $55 \mathrm{~min}$ ), and even in an ambient air atmosphere, at least for a period of minutes [120].

Barrier-type microcavity discharges sustained by sinusoidal voltages in the $\mathrm{kHz}$ range have been used very successfully in generating large arrays of microplasmas [9]. Lesser known, but also very promising, is the use of microwave resonators to generate stable arrays of micro-plasmas between parallel plate electrodes with a single microwave source [12]. Mode coupling allows identical, high-Q resonators to evenly share energy. This effect can, for example, be used to construct linear arrays [121], but also two-dimensional arrays operated from a single microwave power source [12]. An example of a linear array is shown in Figure 45 [122]. The plasma is generated in the area defined by $d$.

A similar linear microdischarge array consisting of 15 microstrip resonators has been used as an optically 


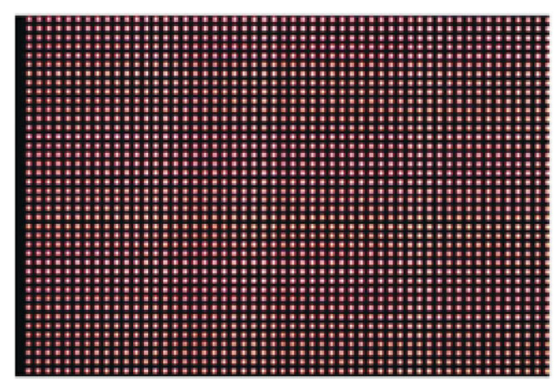

Fig. 43. Photograph of a segment of a $500 \times 500$ discharge panel operated in 700 Torr of $\mathrm{Ne}[2]$.

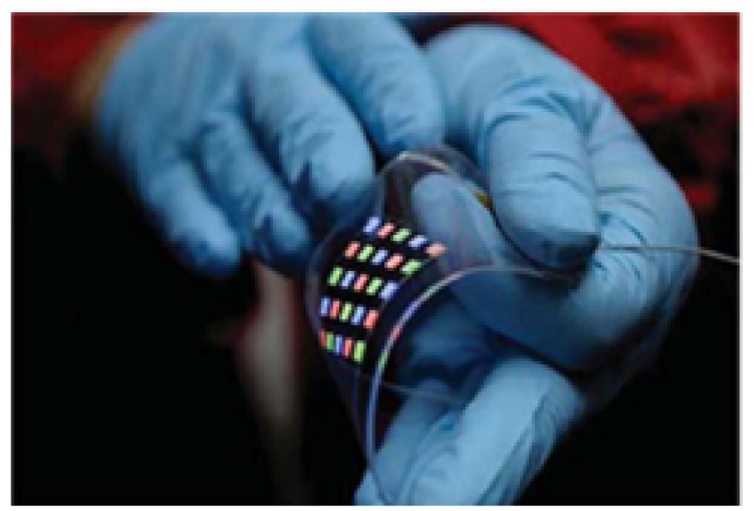

Fig. 44. Photograph of a flexible and transparent $5 \times 5$ array fabricated by replica molding. The gas mixture in each of the $70-\mu \mathrm{m}$ deep cavities is $1 \% \mathrm{~N}_{2}$ in $\mathrm{Ar}$ at a total pressure of 700 Torr. Powering the display is a $\sim 300 \mathrm{~V}$ (RMS), $20-\mathrm{kHz}$ voltage [9].

pumped rare gas laser. The linear array was operated at a frequency of approximately $920 \mathrm{MHz}$ in a mixture of atmospheric-pressure He and $2 \%$ Ar. The plasma was optically pumped with a Ti-sapphire laser at $811.5 \mathrm{~nm}$ causing the optical excitation of the metastable Ar atoms, which led to fluorescence, optical gain, and laser oscillations at $912.3 \mathrm{~nm}[123]$.

\section{Summary}

Microcavity discharges have allowed the generation of stable plasmas at pressures up to and above one atmosphere. They have been operated in a direct current mode, at rf and microwave frequencies, and pulsed with pulse durations as short as a few nanoseconds. They have been operated in rare gases and in molecular gases and mixtures such as atmospheric pressure air. Despite running at high pressures, microdischarges are nonthermal discharges. Their electron energy distribution contains a tail of high energy electrons, which causes high excitation and ionization rates. Electron densities exceeding $10^{16} \mathrm{~cm}^{-3}$ have been measured in pulsed MHC discharges. Gas temperatures, on the other hand, are low compared to temperatures in arcs and sparks. They can be close to room temperature in rare gases and generally reach not more than $2000 \mathrm{~K}$ in atmospheric pressure air discharges. With discharge voltages of a few hundred volts,

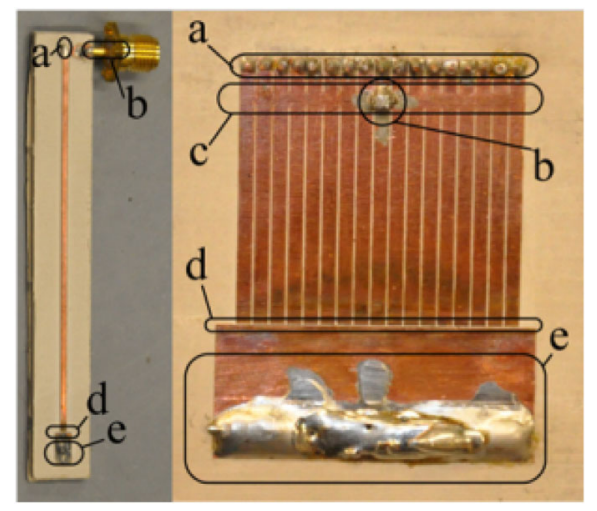

Fig. 45. Single quarter-wave resonator (left) and 16-resonator array (right). The indicated components are (a) vias to the ground plane on the back side, (b) input connector pin, (c) coupling strip (see Sect. 3.2), (d) discharge gap where plasma is generated and (e) ground electrode that is connected to the ground plane on the back side through vias [122].

and current densities on the order of $10 \mathrm{~A} / \mathrm{cm}^{2}$ (at currents of $1 \mathrm{~mA}$ in a MHC discharge with a $100 \mu \mathrm{m}$ cathode opening), the power densities in such a discharge with typical dimensions of $100 \mu \mathrm{m}$ can reach values on the order of $10^{5} \mathrm{~W} \mathrm{~cm}^{-3}$.

The nonthermal characteristics of microdischarges together with other unique features such as stable highpressure operation, high power density, non-Maxwellian electron energy distribution with a significant component of energetic electrons, low gas temperatures (as low as ambient temperature), and the possibility to arrange them in arrays without individual ballasting have led to the development of numerous microplasma devices for a wide range of applications. The possibility to operate microplasmas at high pressure, even exceeding atmospheric pressure, favors three-body reactions, such as excimer generation and formation of certain reactive species. The development of excimer lamps with emissions in the VUV was one of the first application-oriented developments [7]. The same basic mechanism, three-body reactions, has been more recently utilized in microplasma-based ozone generators [124].

The resistive characteristics of microplasmas under certain conditions, and, consequently, the possibility to form large microplasma-arrays led to the development of flat panel light sources consisting of more than $10^{5}$ individual microplasmas. The silicon-based technology on which these flat panels is based, has also been used in addressable flat panels. An overview of recent developments of these devices can be found in a review by Eden et al. [9]. Another area where microplasmas have been successfully introduced is in material processing, particularly the synthesis of nanoparticles $[56,125]$.

More recently, the generation of reactive species in microdischarges, and the ability to transport them in form of plasma jets to biological tissue, has contributed to a rapidly expanding field of research: plasma medicine. Reviews on this novel application of microplasmas are listed as references $[14,15]$. In addition, we refer the reader to the journal "Plasma Medicine", which is a publication 
started in 2011 devoted entirely to papers on plasma medicine [126]. It is important to note that medical applications of plasmas also bear risks, which should be properly assessed [127]. Besides medical applications, studies on environmental applications have been performed (see e.g. Becker [128] and references therein). Lesser known, but important applications of microplasmas, are in the area of detectors [8], and even microthrusters [89].

It is noteworthy to state that the rapid development of microplasma applications in many fields of use has often occurred by trial-and-error, i.e. without having a good understanding of the underlying basic science. Plasma applications as diverse as surface modification and functionalization, light sources, ozone generation, pollution control, biological inactivation, sensors, to name just a few, rely on the plasma-initiated generation of chemically reactive species, in particular reactive oxygen and nitrogen species. While we do have an understanding of some of the key plasma chemical reaction pathways that drive the process in certain applications, this level if insight is lacking in many other areas, most notably in the rapidly growing field of plasma medicine. It is exciting to see how the application of a microplasma can accelerate bold coagulation or stimulate wound healing. However, without insight into the key chemical and biological reaction path ways initiated by the plasma and without an understanding of how the plasma physics governs the key plasma chemical reactions and biomedical processes, there will be a reluctance to move these applications from the research laboratory to full-scale clinical trials, not to mention make these plasma medical methods available in routine patient care.

Moreover, in almost all areas of application we lack a detailed knowledge of the coupling of the plasma physics to the plasma chemistry. We do not yet have the level of understanding of the basic plasma physics that will allow us to tailor the plasma parameters such as gas temperature, power density, electron density, and electron temperature (or more precisely the electron energy distribution) to selectively maximize the generation of certain plasma species, while minimizing or suppressing the formation of others. Thus, we lack the ability to achieve control of the plasma chemistry in many applications by making use of our insight into the basic plasma physics. Lowtemperature plasma physics still requires a continued and sustained investment in basic research.

The authors acknowledge the excellent work of the members of the Organizing Committee and the International Scientific Committee of the 2015 International Workshop on Microplasmas (IWM), where many of the ideas and data that stimulated this Topical Review were presented. Special thanks go to Prof. WeiDong Zhu for his assistance in preparing the IWM key note lecture by one of us (KHS).

\section{References}

1. R. Foest, M. Schmidt, K. Becker, Int. J. Mass Spectrom. 248, 87 (2005)

2. K.H. Becker, K.H. Schoenbach, J.G. Eden, J. Phys. D 39, R55 (2006)
3. K. Tachibana, IEEJ Trans. 1, 145 (2006)

4. F. Iza, G.J. Kim, S.M. Lee, J.K. Lee, J.L. Walsh, Y.T. Zhang, M.G. Kong, Plasma Proc. Polymers 5, 322 (2008)

5. A.P. Papadakis, S. Rossides, A.C. Metaxas, Open Appl. Phys. J. 4, 45 (2011)

6. P. Bruggeman, R. Brandenburg, J. Phys. D 46, 464001 (2013)

7. K.H. Schoenbach, W. Zhu, IEEE J. Quantum Electron. 48, 768 (2012)

8. C.K. Eun, Y. Gianchandani, IEEE J. Quantum Electron. 48, $814(2012)$

9. J.G. Eden, S.-J. Park, J.H. Cho, M.H. Kim, T.J. Houlahan Jr., B. Li, E.S. Kim, T.L. Kim, S.K. Lee, K.S. Kim, J.K. Yoon, S.H. Sung, P. Sun, C.M. Herring, C.J. Wagner, IEEE Trans. Plasma Sci. 41, 661 (2013)

10. X. Lu, M. Laroussi, V. Puech, Plasma Sources Sci. Technol. 21, 034005 (2012)

11. X. Lu, G.V. Neidis, M. Laroussi, K. Ostrikov, Phys. Rep. 540, 123 (2014)

12. J. Hopwood, A.R. Hoskinson, J. Gregorio, Plasma Sources Sci. Technol. 23, 064002 (2014)

13. K. Becker, A. Koutsospyros, S.-M. Yin, C. Christodoulatos, N. Abramzon, J.C. Joaquin, G. Brelles-Mariño, Plasma Phys. Control. Fusion 47, B513 (2005)

14. M.G. Kong, G. Kroesen, G., Morfill, T., Nosenko, T. Shimizu, J. van Dijk, J.L. Zimmermann, New J. Phys. 11, 115012 (2009)

15. M. Laroussi, IEEE Trans. Plasma Sci. 43, 703712 (2015)

16. U. Kogelschatz, Plasma Chem. Plasma Process. 23, 1 (2003)

17. R. Brandenburg, M. Bogaczyk, H. Höft, S. Nemschokmichal, R. Tschiersch, M. Kettlitz, L. Stollenwerk, T. Hoder, R. Wild, K.-D. Weltmann, J. Meichsner, H.-E. Wagner, J. Phys. D 46, 464015 (2013)

18. R. Brandenburg, H.-E. Wagner, A.M. Morozov, K.V. Kozlov, J. Phys. D 38, 1649 (2005)

19. K.V. Kozlov, H.-E. Wagner, R. Brandenburg, P. Michel, J. Phys. D 34, 3164 (2001)

20. J.D. Cobine, Gaseous Conductors, Theory and Engineering Applications (Dover Publications, Inc, New York, 1958), Table 8.3

21. T. Ono, D.Y. Sim, M. Esachi, J. Micromech. Microeng. 10, $445(2000)$

22. G.P. Slade, E.D. Taylor, IEEE Trans. Compon. Packag. Technol. 25, 390 (2002)

23. D.B. Go, A.D. Pohlman, J. Appl. Phys. 107, 103303 (2010)

24. W. Zhang, T.S. Fisher, S.V. Garimella, J. Appl. Phys. 96, $6066(2004)$

25. G. Tirumala, D.B. Go, Appl. Phys. Lett. 97, 151502 (2010)

26. E. Hourdakis, B.J. Simonds, N.M. Zimmerman, Rev. Sci. Instrum. 77, 034702 (2006)

27. R.S. Dhariwal, J.-M. Torres, M.P.Y. Desmulliez, IEE Proc.-Sci. Meas. Technol. 147, 261 (2000)

28. J.-M. Torres, R.S. Dhariwal, Nanotechnology 10, 102 (1999)

29. A. von Engel, Glow Discharge, in Ionized Gases (American Vacuum Society Classics, American Institute of Physics, reprint by arrangement with Oxford University Press, 1965), Chap. 8 
30. A. Von Engel, R. Seeliger, M. Steenbeck, Z. Phys. 85, 144 (1933)

31. D. Staack, B. Farouk, A. Gutsol, A. Fridman, Plasma Sources Sci. Technol. 14, 700 (2005)

32. W. Kaufmann, Ann. Phys. 307, 158 (1900)

33. E.E. Kunhardt, IEEE Trans. Plasma Sci. 28, 189 (2000)

34. V.I. Arkhipenko, A.A. Kirillov, Y.A. Safronau, L.V. Simonchik, Eur. Phys. J. D 60, 455 (2010)

35. M. Moselhy, K.H. Schoenbach, J. Appl. Phys. 95, 1642 (2004)

36. K.H. Schoenbach, M. Moselhy, W. Shi, Plasma Sources Sci. Technol. 13, 177 (2004)

37. N. Takano, K.H. Schoenbach, Plasma Sources Sci. Technol. 15, S109 (2006)

38. W. Zhu, P. Niraula, Plasma Sources Sci. Technol. 23, 054011 (2014)

39. W. Zhu, P. Niraula, P.G.C. Almeida, M.S. Benilov, D.F.N. Santos, Plasma Sources Sci. Technol. 23, 0540012 (2014)

40. M.S. Benilov, Plasma Sources Sci. Technol. 23, 054019 (2014)

41. L. Baars-Hibbe, P. Sichler, C. Schrader, N. Lucas, K.-H. Gericke, S. Buettgenbach, J. Phys. D 38, 510 (2005)

42. C. Schrader, L. Baars-Hibbe, K.-H. Gericke, E.M. van Veldhuizen, N. Lucas, P. Sichler, S. Buettgenbach, Vacuum 80, 1144 (2006)

43. M. McKay, F. Iza, M.G. Kong, Eur. Phys. J. D 60, 497 (2010)

44. K.H. Schoenbach, A. El-Habachi, W. Shi, M. Ciocca, Plasma Sources Sci. Technol. 6, 468 (1997)

45. D.D. Hsu, D.B. Graves, J. Phys. D 36, 2898 (2006)

46. A.D. White, J. Appl. Phys. 30, 711 (1959)

47. K.H. Schoenbach, R. Verhappen, T. Tessnow, F.E. Peterkin, W.W. Byszewski, Appl. Phys. Lett. 68, 13 (1996)

48. C. Penache, M. Miclea, A. Braeuning-Demian, O. Hohn, S. Schoessler, T. Jahnke, K. Niemax, H. SchmidtBoecking, Plasma Sources Sci. Technol. 11, 476 (2002)

49. G. Schaefer, K.H. Schoenbach, Basic Mechanisms Contributing to the Hollow Cathode Effect, in Physics and Applications of Pseudosparks, edited by M. Gundersen, G. Schaefer (Plenum Press, 1990), p. 55

50. K.H. Schoenbach, A. El-Habachi, M.M. Moselhy, W. Shi, R.H. Stark, Phys. Plasmas 7, 2186 (2000)

51. J.P. Bœuf, L.C. Pitchford, K.H. Schoenbach, Appl. Phys. Lett. 86, 071501 (2005)

52. J.W. Frame, D.J. Wheeler, T.A. DeTemple, J.G. Eden, Appl. Phys. Lett. 71, 1165 (1997)

53. S.-J. Park, J.G. Eden, J. Chen, C. Liu, Appl. Phys. Lett. 85, 4869 (2004)

54. A. Fiala, L.C. Pitchford, J.P. Bouef, Two-dimensional, hybrid model of glow discharge in hollow cathode geometries, in 22nd Conf. on Phenomena in Ionized Gases (Hoboken, NJ, 1995), edited by K.H. Becker et al. (Hoboken, NJ, Stevens Institute of Technology), p. 191.

55. R.M. Sankaran, K.P. Giapis, J. Appl. Phys. 92, 2406 (2002)

56. D. Mariotti, R.M. Sankaran, J. Phys. D 43, 23001 (2010)

57. S.-J. Park, J. Chen, Clark J. Wagner, N.P. Ostrom, C. Liu, J.G. Eden, IEEE J. Sel. Top. Quantum Electron. 8, 387 (2002)

58. Z. Yu, K. Hoshimiya, J.D. Williams, S.F. Polvinen, J.G. Collins, Appl. Phys. Lett. 83, 854 (2003)
59. R. Rahul, O. Stan, A. Rahman, E. Littlefield, K. Hoshimiya, A.-P. Yalin A. Sharma, A. Pruden C.A. Moore, Z. Yu, G.J. Collins, J. Phys. D 38, 1750 (2005)

60. Y.D. Wang, J.T. Ouyang, IEEE Trans. Plasma Sci. 36, 1264 (2008)

61. Y.-B. Guo, F.C.-N. Hong, Appl. Phys. Lett. 82, 337 (2003)

62. J.G. Eden, S.-J. Park, Plasma Phys. Controll. Fusion 47, B83 (2005)

63. P.A.Tchertchian, T.M. Sinka, S.-J. Park, J.G. Eden, IEEE Trans. Plasma Sci. 36, 1254 (2008)

64. J.D. Readle, K.E. Tobin, K.S. Kim, J.K. Yoon, J. Zheng, S.K. Lee, S.-J. Park, J.G. Eden, IEEE Trans. Plasma Sci. 37, 1045 (2009)

65. M.H. Kim, J.H. Cho, S,B. Ban, R.Y. Choi, E.J. Kwon, S.-J. Park, J.G. Eden, J. Phys. D 46, 305201 (2013)

66. S.H. Sung, I.C. Hwang, S.-J. Park, J.G. Eden, Appl. Phys. Lett. 97, 231502 (2010)

67. M. Moselhy, W. Shi, R.H. Stark, K.H. Schoenbach, IEEE Trans. Plasma Sci. 30, 198 (2002)

68. M. Moselhy, W. Shi, R.H. Stark, K.H. Schoenbach, Appl. Phys. Lett. 79, 1240 (2001)

69. R.H. Stark, K.H. Schoenbach, J. Appl. Phys. 89, 3568 (2001)

70. B.-J. Lee, H. Rahaman, S.H. Nam, M. Iberler, J. Jacoby, K. Frank, Phys. Plasmas 20, 123510 (2013)

71. J. Stephens, A. Fierro, B. Walls, J. Dickens, A. Neuber, Appl. Phys. Lett. 104, 074105 (2014)

72. K.H. Becker, B.B. Godfrey, E.E. Kunhardt, M. Laroussi, L.D. Ludekind, A.A. Neuber, E. Schamiloglu, A.J. Woods, IEEE Trans. Plasma Sci. 43, 914 (2015)

73. E.E. Kunhardt, K. Becker, L.E. Amorer, Properties of a novel atmospheric-pressure capillary plasma electrode discharge, in Proc. 12th International Conference on Gas Discharges and their Applications, Greifswald, Germany, 1997 , p. I-374

74. L. Moskwinski, P.J. Ricatto, N. Abramzon, K. Becker, G.P. Korfiatis, C. Christodoulatos, Operational characteristics of capillary plasma electrode discharge operating in atmospheric pressure in different gases and gas mixtures, in Proc. XIV Symposium on Applications of Plasma Processes (SAPP), Jasna, Slovakia, 2003, p. 17

75. R.H. Stark, K.H. Schoenbach, J. Appl. Phys. 85, 2075 (1999)

76. R.H. Stark, K.H. Schoenbach, Appl. Phys. Lett. 74, 3770 (1999)

77. A.-A.H. Mohamed, R. Block, K.H. Schoenbach, IEEE Trans. Plasma Sci. 30, 128 (2002)

78. R. Block, O. Toedter, K.H. Schoenbach, Gas Temperature Measurements in High Pressure Glow Discharges in Air, in Proc. 30th AIAA Plasma Dynamics and Lasers Conf., Norfolk, VA, 1999 paper AIAA 99-3434

79. J. Hopwood, F. Iza, S. Coy, D.B. Fenner, J. Phys. D 38, $1698(2005)$

80. P. Kurunczi, N. Abramzon, M. Figus, K. Becker, Acta Physica Slovaca 54, 115 (2004)

81. F. Iza, J. Hopwood, IEEE Trans. Plasma Sci. 32, 498 (2004)

82. T. Verreycken, A.F.H van Gessel, A. Pageau, P. Bruggeman, Plasma Sources Sci. Technol. 20, 024002 (2011)

83. M. Moselhy, I. Petzenhauser, K. Frank, K.H. Schoenbach, J. Phys. D 36, 2922 (2003) 
84. J.L. Walsh, F. Iza, M.G. Kong, Eur. Phys. J. D 60, 523 (2010)

85. S.G. Belostotskiy, R. Khandelwal, Q. Wang, V.M. Donnelly, D.J. Economou, N. Sadeghi, Appl. Phys. Lett. 92, 221507 (2008)

86. F. Leipold, R.H. Stark, A. El-Habachi, K.H. Schoenbach, J. Phys. D 33, 2268 (2000)

87. N. Muira, J. Hopwood, Eur. Phys. J. D 66, 143 (2012)

88. K. Frank, U. Ernst, I. Petzenhauser, W. Hartmann, in Spectroscopic Investigations of High-Pressure Microhollow Cathode Discharges (Conf. Record IEEE Intern. Conf. Plasma Science, Las Vegas, NV, 2001), p. 381

89. M.J. Kushner, J. Phys. D 38, 1633 (2005)

90. G.J. Kim, F. Iza, J.K. Lee, J. Phys. D 39, 4386 (2006)

91. J. Choi, F. Iza, J.K. Lee, C.M. Ryu, IEEE Trans. Plasma Sci. 35, 1274 (2007)

92. C. Schregel, D. Luggenhoelscher, U. Czarnetzki, Bulletin Am. Phys. Soc. 60, 145 (2015)

93. M. Laroussi, T. Arkan, Plasma Proc. Polym. 4, 777 (2007)

94. K.D. Weltmann, E. Kindel, T. von Woedtke, M. Hähnel, M. Stieber, R. Brandenburg, Pure Appl. Chem. 82, 1223 (2010)

95. G.Y. Park, S.J. Park, M.Y. Choi, I.G. Koo, J.H. Byun, J.W. Hong, J.Y. Sim, G.J. Collins, J.K. Lee, Plasma Sources Sci. Technol. 21, 043001 (2012)

96. X. Lu, M. Laroussi, J. Appl. Phys. 100, 063302 (2006)

97. J.K. Kolb, A.-A.H. Mohamed, R.O. Price, R.J. Swanson, A. Bowman, R.L. Chiavarini, M. Stacy, K.H. Schoenbach, Appl. Phys. Lett. 92, 241501 (2008)

98. H. Feng, P. Sun, Y. Chai, G. Tong, J. Zhang, W. Zhu, J. Fang, IEEE Trans. Plasmas Sci. 37, 121 (2009)

99. K.D. Weltmann, E. Kindel, R. Brandenburg, C. Meyer, R. Bussiahan, C. Wilke, T. von Woedtke, Contr. Plasma Phys. 49, 1892 (2009)

100. J. Pan, K. Sun, Y. Liang, P. Sun, J. Zhang, W. Zhu, J. Fang, K.H. Becker, J. Endod. 39, 105 (2013)

101. C. Hoffmann, C. Berganza, J. Zhang, Med. Gas Res. 3, 21 (2013)

102. S.E. Babayan, J.Y. Jeong, V.J. Tu, J. Park, G.S. Selwyn, R.F. Hicks, Plasma, Sources Sci. Technol. 7, 286 (1998)

103. J.Y. Jeong, S.E. Babaya, V.J. Tu, J. Park, I. Hennis, R.F. Hicks, G.S. Selwyn, Sources Sci. Technol. 7, 282 (1998)

104. N. Masoud, K. Martus, K. Becker, Int. J. Mass Spectrom. 233, 395 (2004)

105. N. Masoud, K. Martus, M. Figus, K. Becker, Contr Plasma Phys. 45, 30 (2005)

106. N. Masoud, K. Martus, K. Becker, J. Phys. D 38, 1674 (2005)

107. P. Sun, J. Pan, Y. Tian, N. Bai, H. Wu, L. Wang, C. Yu, F. Liu, S. Wei, Y. Zhou, J. Zhang, W. Zhu, K. Becker, J. Fang, IEEE Trans. Plasma Sci. 38, 1892 (2010)

108. J. Wang, X. Yang, K. Sun, P. Sun, J. Pan, W. Zhu, K. Becker, J. Zhang, J. Fang, IEEE Trans. Plasma Sci. 40, 2157 (2012)

109. F. Liu, P. Sun, N. Bai, Y. Tian, H. Zhou, S. Wei, Y. Zhou, J. Zhang, W. Zhu, K. Becker, J. Fang, Plasma Proc. Polymers 7, 231 (2010)

110. M. Teschke, J. Kedzierski, E.G. Finantu-Dinu, D. Korzec, J. Engemann, IEEE Trans. Plasma Sci. 33, 310 (2005)
111. M. Teschke, J. Kedzierski, J. Engemann, Time and spatially resolved studies of an $\mathrm{kHz}$-excited atmospheric pressure plasma jet for industrial applications, in 48th Annual Technical Conference Proceedings (Society of Vacuum Coaters 505/856-7188 1, 2005, ISSN 0737-5921)

112. El-Habachi, W. Shi, M. Moselhy, R.H. Stark, K.H. Schoenbach, J. Appl. Phys. 88, 3220 (2000)

113. B.A. Vojak, S.-J. Park, C.J. Wagner, J.G. Eden, R. Koripella, J. Burdon, F. Zenhausern, D.L. Wilcox, Appl. Phys. Lett. 78, 1340 (2001)

114. P. von Allmen, D.J. Sadler, C. Jensen, N.P. Ostrom, S.T. McCain, B.A. Vojak, J.G. Eden, Appl. Phys. Lett. 82, 4447 (2003)

115. B.-J.Lee, H. Rahaman, S.H. Nam, K.P. Giapis, M. Iberler, J. Jacoby, K. Frank, Phys. Plasmas 18, 083506 (2011)

116. A.A.-H. Mohamed, Ph.D. Thesis, Old Dominion University, Norfolk, VA, 2004

117. B.-J. Lee, H. Rahaman, S.H. Nam, M. Iberler, C. Teske, J. Jacoby, K. Frank, Appl. Phys. Express 5056001 (2012)

118. W. Zhu, N. Takano, K.H. Schoenbach, D. Guru, J. McLaren, J. Heberlein, R. May, J.R. Cooper, J. Phys. D 40, 3896 (2007)

119. M. Lu, S.-J. Park, B.T. Cunningham, J.G. Eden, IEEE/ASME J. Microelectromechan. Syst. 16, 1397 (2007).

120. Y.-J. Yang, C.-C.Hsu, IEEE Trans. Plasma Sci. 42, 3756 (2014)

121. Z.-H. Zhang, J. Hopwood, Appl. Phys. Lett. 95, 161502 (2009)

122. C. Wu, A.R. Hoskinson, J. Hopwood, Plasma Sources Sci. Technol. 20, 045022 (2011)

123. W.T. Rawlins, K.L. Galbally-Kinney, S.J. Davis, A.R. Hoskinson, J.A. Hopwood, M.C. Heaven, Opt. Exp. 23, $4804(2015)$

124. J.H. Cho, M.H. Kim, C.M. Herring, S.-J. Park, J.G. Eden, in IEEE Intern. Conf. Plasma Sci. (2014), DOI: 10.1109/PLASMA . 2014.7012665

125. R. Wang, S. Zuo, D. Wu, J. Zhang, W. Zhu, K. Becker, J. Fang, Plasma Proc. Poly. 12, 380 (2015)

126. Plasma Medicine, Ed. G. Fridman (Begell House Publications, 2011)

127. J. Lademann. C. Ulrich, A. Patzelt, H. Richter, F. Kluschke, M. Klebes, O. Lademan, A. Kramer, K.D. Weltmann, B. Lange-Asschenfeldt, Clinical Plasma Medicine 1, 5 (2013)

128. K. Becker, The Use of Nonthermal Plasmas in Environmental Applications, chapter 15 in Introduction to Complex Plasmas, in Series on Atomic, Optical, and Plasma Physics, edited by M. Bonitz, N. Horing, P. Ludwig (Springer Verlag, Heidelberg, 2010), Vol. 59

Open Access This is an open access article distributed under the terms of the Creative Commons Attribution License (http://creativecommons.org/licenses/by/4.0), which permits unrestricted use, distribution, and reproduction in any medium, provided the original work is properly cited. 